Article

\title{
A DFT Study of the Geometrical, Spectroscopical and Reactivity Properties of Diindolylmethane-Phenylboronic Acid Hybrids
}

\author{
Amira Jalil Fragoso-Medina, René Gerardo Escobedo-González ${ }^{\mathbb{D}}$, María Inés Nicolás-Vázquez *, \\ Gabriel Arturo Arroyo-Razo, María Olivia Noguez-Córdova and René Miranda-Ruvalcaba \\ Departamento de Ciencias Químicas, Facultad de Estudios Superiores Cuautitlán, Campo 1, \\ Universidad Nacional Autónoma de México, Cuautitlán Izcalli, Estado de Mexico C.P. 54740, Mexico; \\ amirakhali12001@yahoo.com.mx (A.J.F.-M.); renegerardo.escobedo@gmail.com (R.G.E.-G.); \\ garroyo@unam.mx (G.A.A.-R.); olinoco@yahoo.com.mx (M.O.N.-C.); mirruv@yahoo.com.mx (R.M.-R.) \\ * Correspondence: nicovain@yahoo.com.mx; Tel.: +55-56-232-024
}

Received: 13 September 2017; Accepted: 12 October 2017; Published: 17 October 2017

\begin{abstract}
The structure of the ortho-, meta- and para-hybrid diindolylmethane-phenylboronic acids and their interactions were optimized with by a quantum chemical method, using density functional theory at the (DFT) level. Thus, infrared bands were assigned based on the scaled theoretical wavenumbers by correlating the respective experimental data of the molecules. In addition, the corresponding ${ }^{1} \mathrm{H}-/{ }^{13} \mathrm{C}-/{ }^{11} \mathrm{~B}-\mathrm{NMR}$ experimental and theoretical chemical shifts were correlated. The target molecules showed a poor treatment of the $\mathrm{OH}$ shifts in the GIAO method due to the absence of explicit solvent effects in these calculations; therefore, they were explicitly considered with acetone molecules. Moreover, the electron density at the hydrogen bond critical point increased, generating stabilization energy, from weak to moderate or weak to strong, serving as an indicator of the strength of the hydrogen bond between the different intermolecular interactions. Finally, some properties related to the reactive behavior of the target molecules associated with their cytotoxic effects and metabolic pathways were also calculated.
\end{abstract}

Keywords: boronic acids; diindolylmethane; spectroscopy; DFT calculations; hydrogen bonds

\section{Introduction}

Boron-containing compounds are substances with a wide range of potential applications in the fields of material science, supramolecular chemistry, catalysis and biology. In recent years, this class of molecules has become an object of increasing interest due to the bioactive nature of some of them [1]. In particular, the case of boronic acids should be particularly highlighted, since some of have insecticidal, fungicidal, antibacterial and antineoplastic activities, e.g., bortezomib (Velcade ${ }^{\circledR}$ ) [2]. Boron-based compounds also show preferential localization in tumor tissues, thus making possible the so called boron-10 neutron capture therapy $[3,4]$. In addition, the boronic acid moiety has also been used in the synthesis of antitumor and antiviral agents [3,5].

Phenylboronic acids are boronic acid derivatives with some of the previously mentioned biomedical applications, such as diphenylboronic esters with antibacterial activity, or phenylboronic acid (PBA) and diphenylboronic esters (DPBE) which are the most efficient types of boronic acid derivatives that act as serine protease inhibitors decreasing cancer cell viability, being in this application PBA more efficient than boronic acid as the cancer cell viability decreases within eight days [6,7].

On the other hand, 3,3'-dindolylmethane (DIM) is an important organic compound derived from the acid catalyzed condensation of a natural product, indol-3-yl-carbinol (IC3), a molecule produced as an artifact from cruciferous vegetables [8]. I3C is an anti-tumor agent and several studies have 
revealed its clinical efficacy against various epithelial cancers, including endometrial and mammary tumors [9]. Moreover, DIM and some of its analogues (DIMs) are currently among the most popular adjunct therapies for recurrent respiratory papillomatosis due to their effectiveness and low level of toxicity $[10,11]$.

It is also convenient to highlight that modern synthetic chemists currently engage in the synthesis of hybrid molecules, which are made by combining appropriately pieces of different other molecules, in order to synergize or modify the pharmacological activity of the corresponding prototypes. As part of our ongoing research program, we are interested in green chemistry protocols for the production of novel hybrid heterocyclic molecules, and thus we recently reported the synthesis and biological evaluation of three relatively novel hybrid molecules I-III of diindolylmethane and phenylboronic acids [12]; it is important to note that the obtained results were indicative that the hybrid products were promising antineoplastic compounds. To this end the cytotoxic effects of the hybrid molecules were evaluated on six cancer cell lines (U251 = central nervous system glia, PC-3 = prostate, $\mathrm{K} 562=$ leukemia, HCT-15 = colon, MCF-7= breast, SKLU-1 = lung), which evidenced that the meta regioisomer was the most active [12]. Consequently, taking into account the importance of these compounds, we deemed it convenient to report the novel and interesting results of a theoretical study of the target compounds I-III. Using quantum chemistry biological activity predictor methods we determined: (i) the respective conformational analysis; (ii) the fully optimized molecule structures, determining the geometrical parameters: including bond lengths and angles; (iii) also the infrared spectrophotometric data and NMR $\left({ }^{1} \mathrm{H}-,{ }^{13} \mathrm{C}-,{ }^{11} \mathrm{~B}-\right)$ chemical shifts, were determined in the gas-phase and also considering acetone as solvent. Furthermore, (iv) molecular predictions regarding the human metabolism of the target compounds using metaprint 2D were also evaluated.

\section{Results and Discussion}

\subsection{Molecular Parameters}

\subsubsection{Energy}

\section{Conformational Analysis}

In order to calculate the conformers of each regioisomer I-III of the target diindolylmethane phenylboronic acids (Figure 1), they were in a first instance optimized by B3LYP with $6311++G(d, p)$.
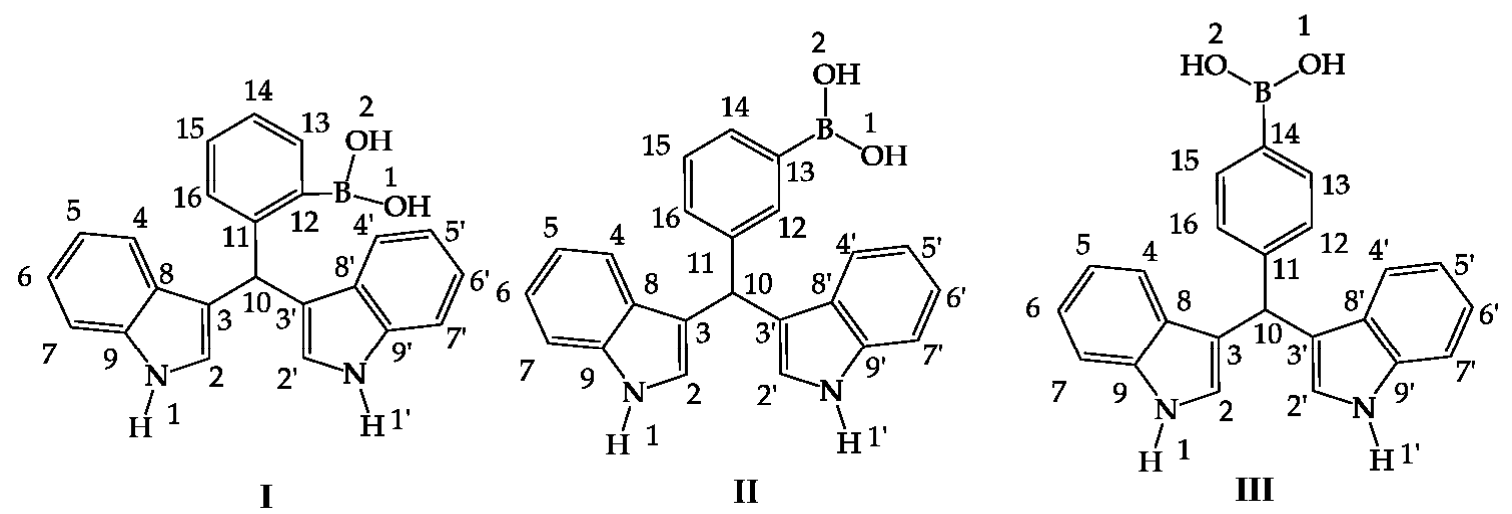

Figure 1. Hybrid diindolylmethane phenylboronic acid regioisomers: ortho (I), meta (II) and para (III).

It is convenient to note that the boronic compounds have three possible conformers depending to the location of the hydrogen atoms bonded to the oxygen atoms in the $-\mathrm{B}(\mathrm{OH})_{2}$ group; consequently, they can be oriented toward the benzene ring (trans-trans $=t t)$, opposite to benzene ring $(c i s-c i s=c c)$ or alternated (cis-trans $=c t$ ) (Figure 2). 


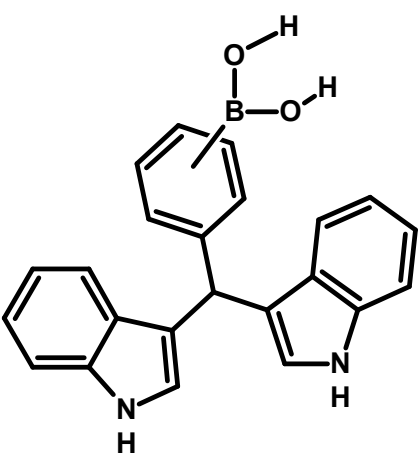

cis-cis $(c c)$

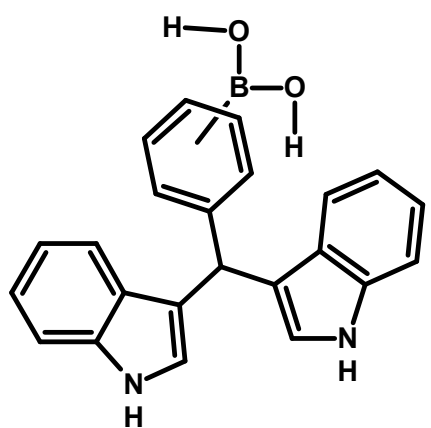

trans-trans $(t t)$

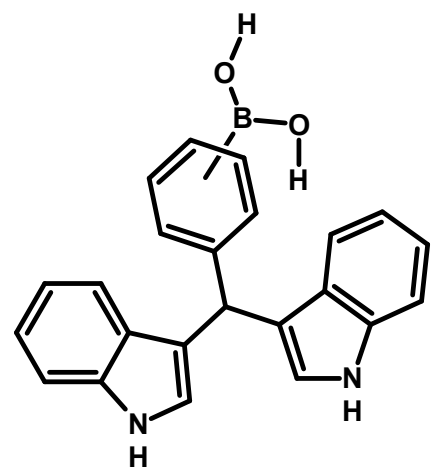

cis-trans (ct)

Figure 2. There is the possibility of forming three possible conformers, this depends on the location of the hydrogen atoms that are bonded to the oxygen atoms of the $-\mathrm{B}(\mathrm{OH})_{2}$ group.

The conformer energy values of the studied compounds are listed in Table 1. The comparison of the values indicates a slight energy difference $(0.7$ to $3.3 \mathrm{kcal} / \mathrm{mol})$, and it can also be seen the the cis-trans configuration resulted as the most stable among the three regioisomers. These results agree with previously reported works for other boronic acids [1,3,13-15]. Among the three possible cis-trans isomers, the $c t$-III appears to be the most stable, followed by the $c t$-II and $c t$-I ones. The energy value difference between the less and more stable ones is $3.1 \mathrm{kcal} / \mathrm{mol}$. The variations in the relative energies among I-III are small, suggesting that these isomers are almost equally stable. The stability of $c t$-III molecule can be attributed to the lower steric effect. These stability results have been previously reported [12].

Table 1. Conformational energy values for I-III.

\begin{tabular}{|c|c|c|c|c|c|c|}
\hline \multirow{3}{*}{ Conformer } & \multicolumn{6}{|c|}{ Isomers } \\
\hline & \multicolumn{2}{|l|}{ I } & \multicolumn{2}{|c|}{ II } & \multicolumn{2}{|c|}{ III } \\
\hline & $\begin{array}{c}\text { Energy } \\
\text { (Hartrees) }\end{array}$ & $\begin{array}{c}\Delta \mathrm{E} \\
(\mathrm{kcal} / \mathrm{mol})\end{array}$ & $\begin{array}{c}\text { Energy } \\
\text { (Hartrees) }\end{array}$ & $\begin{array}{c}\Delta \mathrm{E} \\
(\mathrm{kcal} / \mathrm{mol})\end{array}$ & $\begin{array}{c}\text { Energy } \\
\text { (Hartrees) }\end{array}$ & $\begin{array}{c}\Delta \mathrm{E} \\
(\mathrm{kcal} / \mathrm{mol})\end{array}$ \\
\hline cis-trans $(c t)$ & -1173.13344187 & 0.0 & -1173.13778578 & 0.0 & -1173.13846019 & 0.0 \\
\hline $\begin{array}{c}\text { trans-trans } \\
(t t)\end{array}$ & -1173.13246585 & 0.7 & -1173.13341930 & 2.7 & -1173.13351019 & 3.1 \\
\hline cis-cis (cc) & -1173.12883432 & 3.3 & -1173.13395050 & 2.4 & -1173.13460054 & 2.4 \\
\hline
\end{tabular}

For the optimized structures, the hydrogens atoms were in the O-B-O plane. Most probably, this is due to oxygen lone pair electrons being in resonance with the $p$ orbital empty of the boron, forcing the hydrogens atoms to be in the same plane. In all the conformers of I-III, the boronic acid group was planar and remained in the same plane as the benzene ring or close to it.

\section{C-B Bond Rotational Barrier Analysis}

It is worth nothing that the effect of the aromatic ring and conformational arrangement in the rotational barrier of the $\mathrm{C}-\mathrm{B}$ bond was also studied at the same theory level [3], considering a C12-C13-B-O dihedral angle of $90^{\circ}$ (Table 2). The analyzed conformers for the C-B bond show that the oxygen of the boronic group is in a perpendicular plane, in comparison to the previously evaluated conformer (Table 1). These structures I-III showed imaginary frequencies in all cases, demonstrating that all of them correspond to transition states or unstable structures, and in this sense the difference with the coplanar structure was the energetic barrier for the bond rotation. The energy values of each structure with dihedral angles of $90^{\circ}$, the energies of the coplanar structures and their difference are listed in Table 2. The comparison between the $90^{\circ}$ conformers does not show great energy difference values (between $1.3-5.0 \mathrm{kcal} / \mathrm{mol}$ ). 
Table 2. Relative energy difference between the conformers when the group $-\mathrm{B}(\mathrm{OH})_{2}$ is $90^{\circ}$ of the benzene ring in the systems I: ortho, II: meta and III: para. In each case, the dihedral angle is between $\mathrm{C} 12-\mathrm{C} 13-\mathrm{B}-\mathrm{O}$.

\begin{tabular}{|c|c|c|c|c|c|c|}
\hline \multirow{3}{*}{ Conformer } & \multicolumn{6}{|c|}{ Isomers } \\
\hline & \multicolumn{2}{|c|}{ I $\left(90^{\circ}\right)$} & \multicolumn{2}{|c|}{ II $\left(90^{\circ}\right)$} & \multicolumn{2}{|c|}{ III $\left(90^{\circ}\right)$} \\
\hline & $\begin{array}{c}\text { Energy } \\
\text { (Hartrees) }\end{array}$ & $\begin{array}{c}{ }^{*} \Delta \mathrm{E} \\
(\mathrm{kcal} / \mathrm{mol})\end{array}$ & $\begin{array}{c}\text { Energy } \\
\text { (Hartrees) }\end{array}$ & $\begin{array}{c}{ }^{*} \Delta \mathrm{E} \\
(\mathrm{kcal} / \mathrm{mol})\end{array}$ & $\begin{array}{c}\text { Energy } \\
\text { (Hartrees) }\end{array}$ & $\begin{array}{c}{ }^{*} \Delta \mathrm{E} \\
(\mathrm{kcal} / \mathrm{mol})\end{array}$ \\
\hline cis-trans $(c t)$ & -1173.13188159 & 0.0 & -1173.13317105 & 0.0 & -1773.13273599 & 0.0 \\
\hline $\begin{array}{c}\text { trans-trans } \\
(t t)\end{array}$ & -1173.12910953 & 1.7 & -1173.13082945 & 1.5 & -1173.13071757 & 1.3 \\
\hline cis-cis (cc) & -1173.12453200 & 4.6 & -1173.12514551 & 5.0 & -1173.12527473 & 4.7 \\
\hline
\end{tabular}

* Energies differences relative to more stable conformer: $c t$.

The cis-trans and cis-cis conformers were calculated when the hydrogen atoms were bonded to the oxygen atoms in the $-\mathrm{B}(\mathrm{OH})_{2}$ group are in the plane, and when they are perpendicular $\left(90^{\circ}\right)$. As it can be seen in Table 3, an increasing trend in the rotational barrier is observed, with an increase of the distance between the indolylic and the boronic moiety. The conformers (cis-trans and cis-cis) of I and III displayed the same trend. For $\Delta \mathrm{E}_{\mathrm{I}-\mathrm{I}-90^{\circ}}$, their energy values were 1.0 and $2.7 \mathrm{kcal} / \mathrm{mol}$, respectively, as a consequence of the steric effect due to the proximity of the diindolylmethane moiety. On the other hand, greater rotational barrier values $(2.7$ and $5.9 \mathrm{kcal} / \mathrm{mol}$, respectively) were obtained

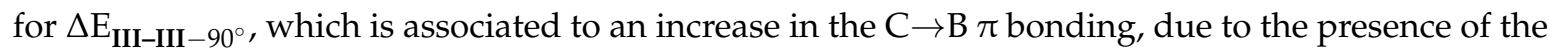
diindolylmethyl group in the $\mathrm{C} 11$ position [16].

Table 3. Effect of the rotation of the boronic acid group on the conformational energy values of the structures for I-III.

\begin{tabular}{|c|c|c|c|c|c|c|}
\hline \multicolumn{7}{|c|}{ Conformer } \\
\hline \multirow{2}{*}{ Isomer } & \multicolumn{2}{|c|}{ cis-trans (ct) } & \multicolumn{2}{|c|}{ trans-trans $(t t)$} & \multicolumn{2}{|c|}{ cis-cis (cc) } \\
\hline & $\begin{array}{c}\text { Energy } \\
\text { (Hartrees) }\end{array}$ & $\begin{array}{c}\Delta \mathrm{E} \\
\text { (kcal/mol) }\end{array}$ & $\begin{array}{c}\text { Energy } \\
\text { (Hartrees) }\end{array}$ & $\begin{array}{c}\Delta \mathrm{E} \\
\text { (kcal/mol) }\end{array}$ & $\begin{array}{c}\text { Energy } \\
\text { (Hartrees) }\end{array}$ & $\begin{array}{c}\Delta \mathrm{E} \\
\text { (kcal/mol) }\end{array}$ \\
\hline $\begin{array}{c}\text { I } \\
\text { I }\left(90^{\circ}\right)\end{array}$ & $\begin{array}{l}-1173.13344187 \\
-1173.13188159\end{array}$ & 1.0 & $\begin{array}{l}-1173.13246585 \\
-1173.12910953\end{array}$ & 2.1 & $\begin{array}{l}-1173.12883432 \\
-1173.12453200\end{array}$ & 2.7 \\
\hline $\begin{array}{c}\text { II } \\
\text { II }\left(90^{\circ}\right)\end{array}$ & $\begin{array}{l}-1173.13778578 \\
-1173.13317105\end{array}$ & 2.9 & $\begin{array}{l}-1173.13341930 \\
-1173.13082945\end{array}$ & 1.6 & $\begin{array}{l}-1173.13395050 \\
-1173.12514551\end{array}$ & 5.5 \\
\hline $\begin{array}{c}\text { III } \\
\text { III }\left(90^{\circ}\right)\end{array}$ & $\begin{array}{l}-1173.13846019 \\
-1773.13273599\end{array}$ & 3.6 & $\begin{array}{l}-1173.13351019 \\
-1173.13071757\end{array}$ & 1.8 & $\begin{array}{l}-1173.13460054 \\
-1173.12527473\end{array}$ & 5.9 \\
\hline
\end{tabular}

The analysis of the trans-trans conformers, calculated when the hydrogen atoms bonded to the oxygen atoms in the $-\mathrm{B}(\mathrm{OH})_{2}$ group are in the plane and when they are perpendicular $\left(90^{\circ}\right)$, revealed a different behavior. The isomer $\mathbf{I}$ possess the greater energy barrier as a consequence of an interaction of the hydrogen atom of the boronic group with an indolyl group in the conformer without torsional effect. This interaction was evaluated by the AIM method, developed by Bader and co-workers, in the analysis of bond critical points of electron density (BCP's), and the gradient paths for the structure $[17,18]$, was discussed in the next section.

The conformational structures of the $p$-regioisomer (maximum stability, III) at $90^{\circ}$ are displayed in Figure 3. All conformers with $90^{\circ}$ have imaginary frequencies. Additionally, some geometrical parameters of the boronic acid group changed.

The $\sigma$ bond distance among C-B increased in all $90^{\circ}$ conformers, as a consequence of scission of conjugation between the aromatic ring and the unoccupied $p$ orbital of the boron atom, present in the boronic acid group. In addition, the difference in C-B bond lengthen conformers $t t$-III and $c t$-III was lower $(0.009 \AA)$, which may be due to the weak interaction between the electronic pi cloud of the benzyl ring, and the hydrogen atoms of the boronic group. Furthermore, the $\mathrm{O}-\mathrm{H}$ and $\mathrm{O}-\mathrm{O}$ bond 
lengths in the boronic acid group increased, while the B-O distance decreased. This behavior, was constant in all the studied isomers.

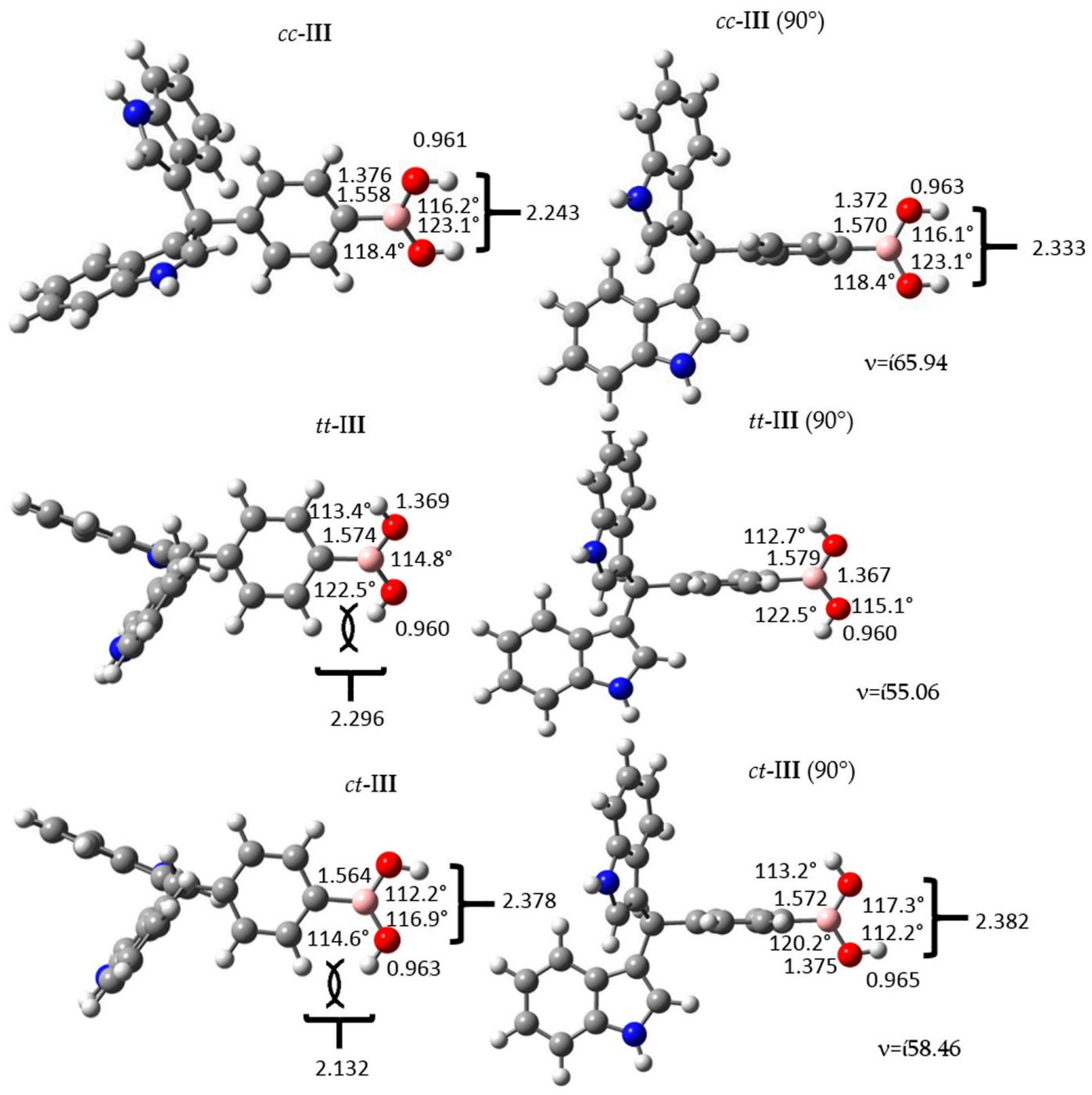

Figure 3. Structure and geometrical parameters of the $p$-diindolylmethane phenylboronic acid hybrid isomers and their corresponding $90^{\circ}$ conformers. The gray, blue, pink, red and white spheres are for carbon, nitrogen, boron, oxygen and hydrogen atoms respectively.

\subsubsection{Geometrical Parameters}

\section{Geometry of I-III}

The bond lengths of the conformers of the studied molecules were determined at the same level of theory (Table 4). The theoretically calculated data did not show great differences in the length, between the conformers; the most significant change in the bond lengths was observed in the boronic groups by the steric or electronic effects associated with their arrangements. Regarding the $c t$ and $t t$ conformers of I, the previously indicated effect of the intramolecular interaction was observed in the C-B distance, which was decreased by the attractive force of $\mathrm{C}^{\prime}$. 
Table 4. Selected theoretical and experimental bond length $(\AA)$ of the conformers for I, II and III.

\begin{tabular}{|c|c|c|c|c|c|c|c|c|c|c|c|c|c|c|c|c|}
\hline \multirow{2}{*}{ Bond } & \multicolumn{5}{|c|}{ I } & \multicolumn{5}{|c|}{ II } & \multicolumn{5}{|c|}{ III } & \multirow{2}{*}{ Exp } \\
\hline & $c t$ & $c c$ & $\Delta_{c c-c t}$ & $t t$ & $\Delta_{t t-c t}$ & $c t$ & $c c$ & $\Delta_{c c-c t}$ & $t t$ & $\Delta_{t t-c t}$ & $c t$ & $c c$ & $\Delta_{c c-c t}$ & $t t$ & $\Delta_{t t-c t}$ & \\
\hline N1-H1 & 1.005 & 1.005 & 0.000 & 1.005 & 0.000 & 1.005 & 1.005 & 0.000 & 1.005 & 0.000 & 1.005 & 1.005 & 0.000 & 1.005 & 0.000 & $0.91^{c}$ \\
\hline $\mathrm{O} 1-\mathrm{H}(\mathrm{O} 1)$ & 0.964 & 0.964 & 0.000 & 0.961 & -0.003 & 0.963 & 0.960 & -0.003 & 0.961 & -0.002 & 0.963 & 0.960 & -0.003 & 0.96 & -0.003 & $0.92^{b}$ \\
\hline $\mathrm{O} 2-\mathrm{H}(\mathrm{O} 2)$ & 0.960 & 0.960 & 0.000 & 0.961 & 0.001 & 0.960 & 0.960 & 0.000 & 0.961 & 0.001 & 0.960 & 0.960 & 0.000 & 0.96 & 0.000 & $0.92^{b}$ \\
\hline N1-C2 & 1.384 & 1.383 & -0.001 & 1.384 & 0.000 & 1.382 & 1.382 & 0.000 & 1.383 & 0.001 & 1.383 & 1.383 & 0.000 & 1.383 & 0.000 & $1.388^{\circ}$ \\
\hline $\mathrm{C} 2-\mathrm{C} 3$ & 1.369 & 1.370 & 0.001 & 1.368 & -0.001 & 1.369 & 1.370 & 0.001 & 1.369 & 0.000 & 1.370 & 1.370 & 0.000 & 1.37 & 0.000 & $1.366^{\circ}$ \\
\hline C3-C10 & 1.513 & 1.513 & 0.000 & 1.513 & 0.000 & 1.513 & 1.513 & 0.000 & 1.513 & 0.000 & 1.515 & 1.515 & 0.000 & 1.515 & 0.000 & $1.508^{\circ}$ \\
\hline $\mathrm{N} 1^{\prime}-\mathrm{C} 2^{\prime}$ & 1.384 & 1.381 & -0.003 & 1.384 & 0.000 & 1.383 & 1.383 & 0.000 & 1.383 & 0.000 & 1.383 & 1.382 & -0.001 & 1.383 & 0.000 & $1.379^{\mathrm{b}}$ \\
\hline $\mathrm{C} 2^{\prime}-\mathrm{C}^{\prime}$ & 1.371 & 1.374 & 0.003 & 1.370 & -0.001 & 1.370 & 1.370 & 0.000 & 1.370 & 0.000 & 1.369 & 1.370 & 0.001 & 1.369 & 0.000 & $1.370^{\circ}$ \\
\hline $\mathrm{C} 3^{\prime}-\mathrm{C} 10$ & 1.515 & 1.517 & 0.002 & 1.515 & 0.000 & 1.515 & 1.515 & 0.000 & 1.515 & 0.000 & 1.513 & 1.513 & 0.000 & 1.513 & 0.000 & $1.513^{\mathrm{b}}$ \\
\hline C10-C11 & 1.536 & 1.538 & 0.002 & 1.538 & 0.002 & 1.531 & 1.532 & 0.001 & 1.532 & 0.001 & 1.530 & 1.530 & 0.000 & 1.53 & 0.000 & $1.518^{\mathrm{b}}$ \\
\hline C11-C12 & 1.415 & 1.414 & -0.001 & 1.417 & 0.002 & 1.395 & 1.395 & 0.000 & 1.395 & 0.000 & 1.399 & 1.398 & -0.001 & 1.399 & 0.000 & $1.372^{\mathrm{b}}$ \\
\hline $\mathrm{C} 12-\mathrm{C} 13$ & 1.406 & 1.406 & 0.000 & 1.406 & 0.000 & 1.405 & 1.405 & 0.000 & 1.405 & 0.000 & 1.390 & 1.391 & 0.001 & 1.39 & 0.000 & $1.384^{\mathrm{b}}$ \\
\hline C13-C14 & 1.392 & 1.392 & 0.000 & 1.391 & -0.001 & 1.403 & 1.403 & 0.000 & 1.403 & 0.000 & 1.405 & 1.405 & 0.000 & 1.404 & -0.001 & $1.385^{\mathrm{b}}$ \\
\hline C14-C15 & 1.390 & 1.391 & 0.001 & 1.390 & 0.000 & 1.392 & 1.393 & 0.001 & 1.392 & 0.000 & 1.402 & 1.404 & 0.002 & 1.403 & 0.001 & $1.374^{\mathrm{b}}$ \\
\hline C15-C16 & 1.394 & 1.393 & -0.001 & 1.393 & -0.001 & 1.392 & 1.392 & 0.000 & 1.393 & 0.001 & 1.392 & 1.393 & 0.001 & 1.392 & 0.000 & $1.374^{\mathrm{b}}$ \\
\hline C16-C11 & 1.396 & 1.397 & 0.001 & 1.397 & 0.001 & 1.398 & 1.398 & 0.000 & 1.398 & 0.000 & 1.396 & 1.396 & 0.000 & 1.397 & 0.001 & $1.378^{\mathrm{b}}$ \\
\hline C12-B & 1.573 & 1.584 & 0.011 & 1.569 & -0.004 & - & - & & - & - & - & - & - & - & - & $1.579^{\mathrm{b}}$ \\
\hline C13-B & - & - & - & - & - & 1.565 & 1.575 & 0.010 & 1.559 & -0.006 & - & - & - & - & - & $1.579^{\mathrm{b}}$ \\
\hline C14-B & - & - & - & - & - & - & - & & - & - & 1.563 & 1.574 & 0.011 & 1.557 & -0.006 & $1.579^{\mathrm{b}}$ \\
\hline B-O1 & 1.367 & 1.372 & 0.005 & 1.374 & 0.007 & 1.368 & 1.368 & 0.000 & 1.375 & 0.007 & 1.368 & 1.368 & 0.000 & 1.376 & 0.008 & $1.355^{\mathrm{b}}$ \\
\hline $\mathrm{B}-\mathrm{O} 2$ & 1.375 & 1.362 & -0.013 & 1.377 & 0.002 & 1.375 & 1.368 & -0.007 & 1.376 & 0.001 & 1.375 & 1.369 & -0.006 & 1.376 & 0.001 & $1.362^{\mathrm{b}}$ \\
\hline
\end{tabular}

${ }^{a}$ Value obtained from Kumar et al., [19]; ${ }^{b}$ Value obtained from Kurt [14]; ${ }^{c}$ Value obtained from Maciejewska et al., [20] for 5,5-dicyano-3,3'-bis(diindolyl)methane. 
Since the experimental X-rays patterns of the target molecules have not been yet published, and considering the motifs present in these molecules $[1,3,12,14,19,21,22]$, the obtained values were compared by the same motif previously reported in other compounds $[14,19,20]$. In this sense, the calculated values were agreed with the previously reported data, considering the structural differences with the reference molecules. Taking into account the most stable conformer $(c t)$, the C-B bond distance in the three target molecules was lower than the reference (pentafluorophenylboronic acid) [14], this difference was attributed to the absence of the fluorine atoms in the latter structure [14,22]. Furthermore, the comparison of the same conformer $(c t)$ of the three analyzed compounds, the distance C-B in $\mathbf{I}$ is greater than II and III; this increase was considered a result of the steric stress between the boronic acid group and the indolylic moiety.

Additionally, the distance of the bond B-O increased in the target molecules, in comparison with the reference, indicating less delocalization of the unshared electron pair of the oxygen to the boron atom as a consequence of the lack of fluorine atoms in the aromatic ring.

Following the geometrical parameters, the calculated bond angles (Table 5) in the considered conformers were contrasted. These parameters, as expected, were very similar in the phenyl and indolylic moieties [20], the biggest changes being observed for the boronic acid group. Related to the boronic acid group angles, the $t t$ conformers showed higher values in regard to other conformers, except in the case of the $\mathrm{C}-\mathrm{B}-\mathrm{O}$ motif, which presented in all cases the smallest angle value. The theoretical angle was compared with the same references, observing that they are in agreement with the corresponding experimental values. Thus, it is important to note, that the best approach of the angle values corresponded to $\mathbf{I}$ in its $c t$ conformer, according to the experimental values.

The molecule III, the most stable under consideration, was characterized by the presence of intermolecular interactions, which can be decisive in the crystal packing of this kind of products. It is worth noting that in previous works the structural crystal description of some phenylboronic acid derivatives has been reported. According, to a low-temperature study, for the unsubstituted phenylboronic acid crystals [22], they were formed by an asymmetric unit, composed by two molecules of the acid, achieving a dimer. The study with III was made assessing that a dimer structure and the non-covalent interaction could be present. The proposed interactions will be discussed later in the paper. 
Table 5. Selected theoretically and experimental bond angles $\left({ }^{\circ}\right)$ of the conformers of the target molecules.

\begin{tabular}{|c|c|c|c|c|c|c|c|c|c|c|c|c|c|c|c|c|}
\hline \multirow{2}{*}{ Bond Angle } & \multicolumn{5}{|c|}{$\mathbf{I}$} & \multicolumn{5}{|c|}{ II } & \multicolumn{5}{|c|}{ III } & \multirow{2}{*}{ Exp } \\
\hline & $c t$ & $c c$ & $\Delta_{c c-c t}$ & $t t$ & $\Delta_{t t-c t}$ & $c t$ & $c c$ & $\Delta_{c c-c t}$ & $t t$ & $\Delta_{t t-c t}$ & $c t$ & $c c$ & $\Delta_{c c-c t}$ & $t t$ & $\Delta_{t t-c t}$ & \\
\hline C9-N1-C2 & 109.20 & 109.20 & 0.00 & 109.20 & 0.00 & 109.30 & 109.20 & -0.10 & 109.20 & -0.10 & 109.20 & 109.20 & 0.00 & 109.20 & 0.00 & $108.70^{\mathrm{l}}$ \\
\hline C3-C10-C11 & 113.40 & 113.40 & 0.00 & 113.70 & 0.30 & 112.90 & 113.10 & 0.20 & 113.10 & 0.20 & 111.40 & 113.10 & 1.70 & 111.40 & 0.00 & $113.11^{\circ}$ \\
\hline $\mathrm{C} 9^{\prime}-\mathrm{N} 1^{\prime}-\mathrm{C} 2^{\prime}$ & 109.20 & 109.30 & 0.10 & 109.20 & 0.00 & 109.30 & 109.20 & -0.10 & 109.20 & -0.10 & 109.20 & 109.20 & 0.00 & 109.20 & 0.00 & $108.80^{\mathrm{l}}$ \\
\hline $\mathrm{C} 3^{\prime}-\mathrm{C} 10-\mathrm{C} 11$ & 111.10 & 111.30 & 0.20 & 111.00 & -0.10 & 111.60 & 111.50 & -0.10 & 111.60 & 0.00 & 113.10 & 111.40 & -1.70 & 113.10 & 0.00 & 110.60 \\
\hline C11-C12-C13 & 118.20 & 118.00 & -0.20 & 118.20 & 0.00 & 122.00 & 122.40 & 0.40 & 121.80 & -0.20 & 121.00 & 120.90 & -0.10 & 120.90 & -0.10 & $119.20^{\mathrm{l}}$ \\
\hline C12-C13-C14 & 122.10 & 122.10 & 0.00 & 122.10 & 0.00 & 117.90 & 117.60 & -0.30 & 118.40 & 0.50 & 121.30 & 121.60 & 0.30 & 121.10 & -0.20 & $123.00^{\mathrm{l}}$ \\
\hline C14-C15-C16 & 119.90 & 119.80 & -0.10 & 119.90 & 0.00 & 119.90 & 120.00 & 0.10 & 120.00 & 0.10 & 121.80 & 121.80 & 0.00 & 121.40 & -0.40 & $123.00^{\mathrm{l}}$ \\
\hline C15-C16-C11 & 121.50 & 121.40 & -0.10 & 121.60 & 0.10 & 120.80 & 120.70 & -0.10 & 120.90 & 0.10 & 121.50 & 120.70 & -0.80 & 120.70 & -0.80 & $119.40^{\mathrm{b}}$ \\
\hline $\mathrm{B}-\mathrm{C} 12-\mathrm{C} 13$ & 116.90 & 117.10 & 0.20 & 116.00 & -0.90 & - & - & - & - & - & - & - & - & - & - & $121.90^{\mathrm{l}}$ \\
\hline $\mathrm{C} 12-\mathrm{B}-\mathrm{O} 1$ & 121.30 & 124.30 & 3.00 & 121.10 & -0.20 & - & - & - & - & - & - & - & - & - & - & $118.20^{\mathrm{l}}$ \\
\hline $\mathrm{C} 12-\mathrm{B}-\mathrm{O} 2$ & 121.90 & 120.70 & -1.20 & 116.90 & -5.00 & - & - & - & - & - & - & - & - & - & - & $122.20^{\mathrm{l}}$ \\
\hline $\mathrm{C} 12-\mathrm{C} 13-\mathrm{B}$ & - & - & - & - & - & 119.90 & 121.00 & 1.10 & 120.80 & 0.90 & - & - & - & - & - & $121.90^{\mathrm{l}}$ \\
\hline B-C13-C14 & - & - & - & - & - & 122.20 & 121.40 & -0.80 & 120.90 & -1.30 & - & - & - & - & - & $122.70^{\mathrm{t}}$ \\
\hline C13-B-O1 & - & - & - & - & - & 119.00 & 122.50 & 3.50 & 118.50 & -0.50 & - & - & - & - & - & $118.20^{\mathrm{l}}$ \\
\hline $\mathrm{C} 13-\mathrm{B}-\mathrm{O} 2$ & - & - & - & - & - & 124.10 & 122.60 & -1.50 & 118.40 & -5.70 & - & - & - & - & - & $122.20^{\mathrm{l}}$ \\
\hline C13-C14-B & - & - & - & - & - & - & - & - & - & - & 120.20 & 121.60 & 1.40 & 121.20 & 1.00 & $121.90^{\mathrm{l}}$ \\
\hline B-C14-C15 & - & - & - & - & - & - & - & - & - & - & 122.70 & 121.60 & -1.10 & 121.20 & -1.50 & $122.70^{\mathrm{l}}$ \\
\hline C14-B-O1 & - & - & - & - & - & - & - & - & - & - & 118.80 & 122.60 & 3.80 & 118.40 & -0.40 & $118.20^{\mathrm{t}}$ \\
\hline $\mathrm{B}-\mathrm{O} 2-\mathrm{H}(\mathrm{O} 2)$ & 113.70 & 113.00 & -0.70 & 115.80 & 2.10 & 114.40 & 113.40 & -1.00 & 116.10 & 1.70 & 114.60 & 113.30 & -1.30 & 116.20 & 1.60 & $115.60^{\mathrm{l}}$ \\
\hline O1-B-O2 & 116.70 & 114.90 & -1.80 & 122.00 & 5.30 & 116.90 & 114.90 & -2.00 & 126.10 & 9.20 & 116.90 & 114.80 & -2.10 & 123.10 & 6.20 & $119.50^{\mathrm{l}}$ \\
\hline
\end{tabular}

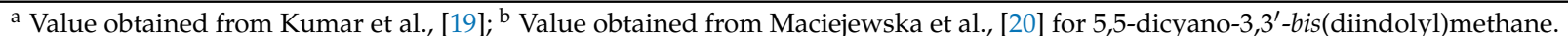


Intramolecular Interaction for Molecule I

As previously described, the intramolecular interaction present in the $t$-I conformer was analyzed by the AIM method. These results are displayed in Figure 4, the molecular graph shows the bond critical points of electron density (BCP's) $(3,-1)$ located at $\mathrm{OH} \bullet \bullet \bullet \mathrm{CH}$, and this contact suggests the existence of a chemical interaction. In fact, the density $\rho(r)$ was $0.0089 \mathrm{e} / \mathrm{a} . \mathrm{u}^{3}{ }^{3}$ and the Laplacian $\nabla^{2} \rho(r)$ was -0.0093 e/a.u. ${ }^{5}$ meanwhile the ring critical point $(\mathrm{RCP})(3,+1)$ had a density value $(\rho(r))$ of $0.0135 \mathrm{e} / \mathrm{a} . \mathrm{u}^{3}$ and the $\nabla^{2} \rho(r)$ was $-0.0094 \mathrm{e} / \mathrm{a} . \mathrm{u}^{5}$. The negative Laplacian values indicated a local concentration of charge, suggesting an interaction of the lone electron pair type or Lewis base, as a model of reactivity [21]. This behavior can be explained by means of a resonance effect of the non-shared electron pair of the nitrogen atom within the indole ring, causing the presence of an electronic pair in the C-3' position of the indole ring and the attraction of the hydrogen atom.

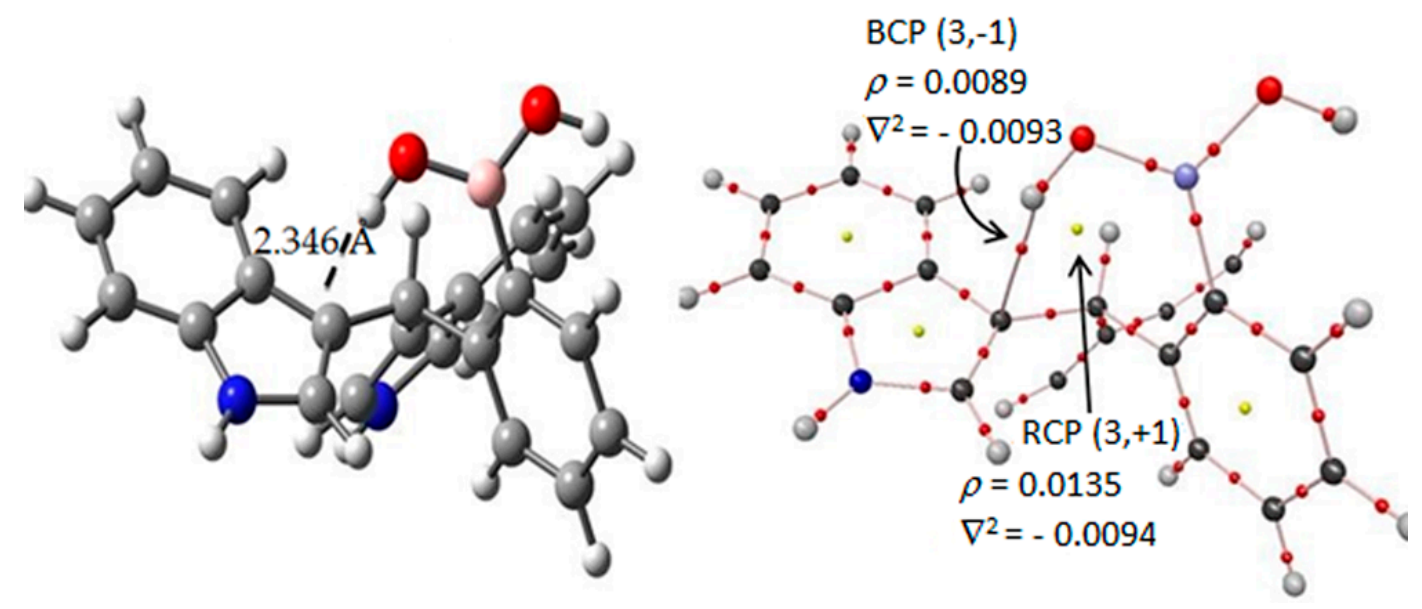

Figure 4. AIM results of the hydrogen-C $3^{\prime}$ interaction in the $t t$-I diindolylmethane-phenylboronic acid hybrid. Molecular graphs for $t$-ortho-regioisomer interaction. Density $\rho(r)$ and its Laplacian $\nabla^{2} \rho(r)$ at the BCPs characterizing the HB interactions. The gray, blue, pink, red and white spheres are for carbon, nitrogen, boron, oxygen and hydrogen atoms respectively.

As a consequence of this interaction a large rotational energy barrier was achieved. This is in addition to the lower energy difference values between the cis-trans and trans-trans conformers of I (Table 1) resulting in the stabilization effect of this interaction. Regarding II and III in the trans-trans conformers the energy barriers provided the same behavior, previously mentioned, however the $t t$-conformers have less energy difference than the $c c$ and $c t$ conformers. This decrease was attributed to a steric repulsion between the hydrogen of the boronic acid group and the hydrogen at C-13 $(-\mathrm{OH} \bullet \bullet \bullet \mathrm{H}-\mathrm{C} 13$ length around $2.2 \AA)$ by the hydrogen orientation; this repulsion 0 .indicated that the boronic acid groups do not stay in the same plane of the benzene ring.

Intermolecular Interactions for Molecule III-2

The presence of eight dimeric structures was observed. In this sense, two principal intermolecular interactions were found: (a) hydrogen bonds between the hydrogen atoms of the boronic acid group (III-1 and III-3, Figure 5) or the N-H bond of the indolylic moiety with the same groups, the boronic acid groups (III-2 and III-6, Figure 5), and (b) the hydrogen of the boronic acid or N-H bond of the indolyl group, with the $\pi$-aromatic systems (III-2, III-4, III-5, III-7 and III-8, Figure 5). The corresponding electronic and interaction energies values for the dimers are summarized in Table 5. The first dimer analyzed was III-1, which according to Figure 5, presented two intermolecular hydrogen bonds among the boronic acid groups; a smaller distance between the acceptors and donors (approximately $1.86 \AA$ ) and an angle closer to $178.7^{\circ}$ that indicated a strong intermolecular interaction. Additionally, the electronic energy and the interaction energy showed bigger values in 
contrast with the other dimers, confirming the stronger character of these hydrogen bonds. This type of dimer has been previously reported for the crystalline structure of phenylboronic acid [22] and these theoretical values agree with the experimental data reported for phenylboronic acid (distances: hydrogen-acceptor $1.81 \AA$, between donor and oxygen acceptor $2.72 \AA$ and bond angle $175^{\circ}$ ).

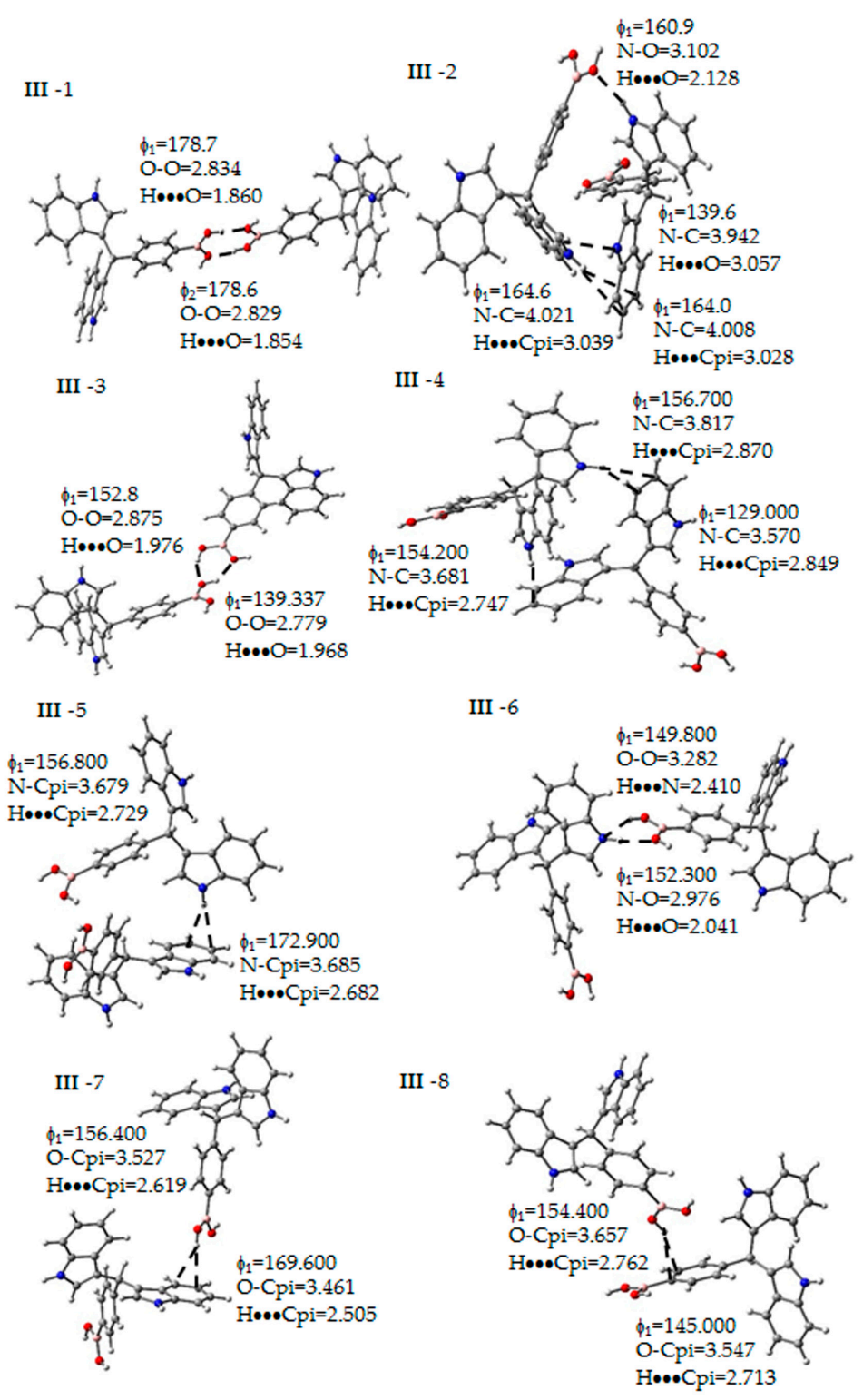

Figure 5. Non-covalent interactions determined between the molecules of III. Some geometrical parameters as bond length and angle are next to the bond. The gray, blue, pink, red and white spheres are for carbon, nitrogen, boron, oxygen and hydrogen atoms respectively.

Additionally, there is a different kind of hydrogen bonds between the boronic acid groups, as can be seen by comparing III-3 and III-1. The III-3 dimer revealed the presence of a bifurcate acceptor in the hydrogen bond [23], decreasing the stability of the interaction, in comparison with III-1, due to the increase $(1.97 \AA)$ of the bond length and the decrease of the angle value $\left(130^{\circ}-150^{\circ}\right)$. Finally, III-6 showed hydrogen bonds between a boronic acid group and the $\mathrm{N}-\mathrm{H}$ of the indole motif, and the interaction properties (Table 6 and Figure 5) indicated a weaker bond [23], distance of 2-2.4 $\AA$, $\Phi$ around $\left.150^{\circ}\right)$ and the interaction energy exhibited the lower value $(-2.5 \mathrm{kcal} / \mathrm{mol})$ than the dimers with only hydrogen bonds. 
Regarding the dimers III-2, III-4 and III-5, they presented an interaction between hydrogen atoms and the $\pi$-aromatic systems of the indoles; this type of interaction has been previously described [20,24]. In the references, the crystal packaging of the molecules is stabilized by different weak intermolecular contacts such as the hydrogen bonds and they were formed by means of folded layers. Moreover, the cohesion between these layers results from the $\mathrm{C}-\mathrm{H} \bullet \bullet \bullet \pi$ intermolecular interactions, and analogous $\mathrm{N}-\mathrm{H} \bullet \bullet \bullet \pi$ contacts, were observed for $3,3^{\prime}$-diindolylmethane derivatives $[20,24]$. Concerning the calculated bond parameters, the distances between the hydrogen and the $\pi$-system are 2.500 to $3.000 \AA$; additionally, the bond angles had values between $150^{\circ}-170^{\circ}$, which are in agreement with the values obtained for 3,3'-diindolylmethane derivatives that had a bond distance of 2.750 and $2.470 \AA$, and the bond angle are in the range of $148^{\circ}$ and $171^{\circ}$. According to the second kind of the interaction, $\mathrm{N}-\mathrm{H} \bullet \bullet \bullet \pi$, the most stable of this group of dimers was III-2, which additionally, has a hydrogen bond among the boronic acid and indolylic moiety, while the III-7 dimer presented an interaction between the hydrogen atoms of the boronic acid group and the $\pi$-aromatic system of the indole and the dimer III-8 indicating an interaction between a hydrogen atom of the boronic acid group and the $\pi$-aromatic system near the boronic acid group.

Table 6. Energetic properties of the eight dimers found.

\begin{tabular}{cccc}
\hline Dimer & Electronic Energy (Hartrees) & IE (kcal/mol) & RE (kcal/mol) \\
\hline III-1 & -2346.28916998 & -7.7 & 0.0 \\
III-2 & -2346.28480554 & -4.9 & 2.7 \\
III-3 & -2346.28456653 & -4.8 & 2.9 \\
III-4 & -2346.28343557 & -4.1 & 3.6 \\
III-5 & -2346.28249966 & -3.5 & 4.2 \\
III-6 & -2346.28131638 & -2.8 & 4.9 \\
III-7 & -2346.28044096 & -2.2 & 5.5 \\
III-8 & -2346.27761899 & -0.4 & 7.3 \\
\hline \multicolumn{5}{c}{}
\end{tabular}

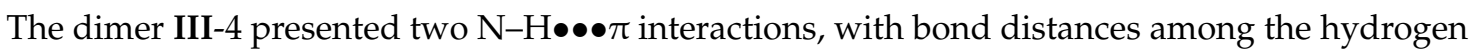
and $\pi$ system in the range of 2.7-2.8 $\AA$, acceptor and donor between 3.6-3.8 $\AA$ and bond angles of $150^{\circ}$ and $152^{\circ}$. This corresponds to weak hydrogen bonds [23]. Finally, III-5 has only one interaction of this type; it was the most unstable dimer of the group.

Complementarily, considering the dimers, and using the atoms in molecules methodology to find the critical points of electron density in order to obtain the parameters $\rho(r)$ and the Laplacian $\nabla^{2} \rho(r)$, were studied. The corresponding values are summarized in Table 7; also, Figure 6 shows the structure with the critical points $(3,-1)$ and $(3,+1)$. These results confirmed the presence of the interactions, having positive density values, with respect to the $\mathrm{OH} \bullet \bullet \bullet \mathrm{OH}$ and $\mathrm{NH} \bullet \bullet \bullet \mathrm{OH}$ interactions, the values were in the order of $10^{-2} \mathrm{e} / \mathrm{a} . \mathrm{u}^{3}{ }^{3}$, typical data of the range of hydrogen bond [25]. In this sense, the density values of the hydrogen atom $\bullet \bullet \pi$ system and the critical points of rings showed values in the order of $10^{-3} \mathrm{e} / \mathrm{a} . \mathrm{u}^{3}$ corresponding to Van der Walls complexes [26]. Thus, all of the Laplacian values were negative, indicating a local charge concentration [21], assigned to a shared interaction, corresponding to the typical valence shell charge concentration $[21,25,26]$. 
Table 7. Values of electronic density and the square Laplacian of density for the dimers.

\begin{tabular}{|c|c|c|c|c|c|c|c|}
\hline Dimer & Interaction & $\rho$ & $\nabla^{2} \rho$ & Dimer & Interaction & $\rho$ & $\nabla^{2} \rho$ \\
\hline \multirow{3}{*}{1} & $\mathrm{BCP}(3,-1) \mathrm{O} 1 \mathrm{H} \bullet \bullet \bullet \mathrm{O} 1 \mathrm{H}$ & 0.0289 & -0.0264 & \multirow{3}{*}{5} & $\mathrm{BCP}(3,-1) \mathrm{N}-\mathrm{H} 1 \bullet \bullet \pi$ indol & 0.0063 & -0.0045 \\
\hline & $\mathrm{BCP}(3,-1) \mathrm{O} 2 \mathrm{H} \bullet \bullet \bullet \mathrm{O} 2 \mathrm{H}$ & 0.0293 & -0.0267 & & BCP $(3,-1) \mathrm{C}-\mathrm{H} 2 \bullet \bullet \bullet \pi$ & 0.0034 & -0.0027 \\
\hline & $\operatorname{RCP}(3,+1)$ & 0.0043 & -0.0053 & & $\operatorname{RCP}(3,+1)$ & 0.0034 & -0.0028 \\
\hline \multirow{6}{*}{2} & $\mathrm{BCP}(3,-1) \mathrm{O} 1 \mathrm{H} \bullet \bullet \bullet N H 1$ & 0.0165 & -0.0149 & \multirow{6}{*}{6} & \multirow{2}{*}{$\mathrm{BCP}(3,-1) \mathrm{O} 1 \mathrm{H} \bullet \bullet \mathrm{N}$} & \multirow[t]{2}{*}{0.0110} & \multirow[t]{2}{*}{-0.0083} \\
\hline & $\begin{array}{c}\mathrm{BCP}(3,-1) \mathrm{CH} 2 \text { indol } \bullet \bullet \pi \\
\text { boronic }\end{array}$ & 0.0037 & -0.0026 & & & & \\
\hline & $\begin{array}{c}\mathrm{RCP}(3,+1) \mathrm{C}-\mathrm{H} 2 \bullet \bullet \bullet \pi \\
\mathrm{O} 1 \mathrm{H} \bullet \bullet \mathrm{NH} 1\end{array}$ & 0.0023 & -0.0023 & & \multirow[t]{2}{*}{$\mathrm{BCP}(3,-1) \mathrm{NH} 1 \bullet \bullet \bullet \mathrm{O} 2$} & \multirow[t]{2}{*}{0.0202} & \multirow[t]{2}{*}{-0.0191} \\
\hline & $\mathrm{BCP}(3,-1) \mathrm{N} \bullet \bullet-\mathrm{H} 2-\mathrm{C}$ indol & 0.0036 & -0.0027 & & & & \\
\hline & $\mathrm{BCP}(3,-1) \mathrm{N}-\mathrm{H} 1 \pi \bullet \bullet \bullet$ indol & 0.0038 & -0.0029 & & \multirow[t]{2}{*}{$\operatorname{RCP}(3,+1)$} & \multirow[t]{2}{*}{0.0075} & \multirow[t]{2}{*}{-0.0081} \\
\hline & $\begin{array}{c}\mathrm{RCP}(3,+1) \mathrm{N} \bullet \bullet \bullet \mathrm{H}-\mathrm{C} \text { indol } \\
\mathrm{N}-\mathrm{H} 1 \bullet \bullet \bullet \pi \text { indol }\end{array}$ & 0.0026 & -0.0024 & & & & \\
\hline \multirow{5}{*}{3} & $\mathrm{BCP}(3,-1) \mathrm{O} 1 \mathrm{H} \bullet \bullet \bullet \mathrm{O} 1$ & 0.0223 & -0.0211 & \multirow{5}{*}{7} & $\mathrm{BCP}(3,-1) \mathrm{O} 1 \mathrm{H} \bullet \bullet \bullet \pi$ indol & 0.0047 & -0.0030 \\
\hline & $\mathrm{RCP}(3,-1) \mathrm{O} 1 \mathrm{H} \bullet \bullet \bullet 2$ & 0.0231 & -0.0226 & & $\mathrm{BCP}(3,-1) \mathrm{C}-\mathrm{H} 2 \bullet \bullet \bullet \pi$ & 0.0042 & -0.0032 \\
\hline & $\mathrm{RCP}(3,+1)$ & 0.0098 & -0.0121 & & $\mathrm{BCP}(3,-1) \mathrm{CH} \bullet \bullet \bullet$ & 0.0027 & -0.0022 \\
\hline & & & & & $\mathrm{RCP}(3,+1) \mathrm{CH} \bullet \bullet \bullet \pi \mathrm{OH} \bullet \bullet \bullet \pi$ & 0.0027 & -0.0022 \\
\hline & & & & & $\mathrm{RCP}(3,+1) \mathrm{OH} \bullet \bullet \pi \mathrm{CH} \bullet \bullet \mathrm{O}$ & 0.0010 & -0.0009 \\
\hline \multirow{6}{*}{4} & $\operatorname{BCP}(3,-1) \mathrm{NH} 1 \bullet \bullet \pi$ indol $^{1}$ & 0.0057 & -0.0039 & \multirow{6}{*}{8} & $\mathrm{BCP}(3,-1) \mathrm{C}-\mathrm{H} 2 \bullet \bullet \bullet \mathrm{O} 2$ & 0.0033 & -0.0031 \\
\hline & $\mathrm{BCP}(3,-1) \mathrm{C}-\mathrm{H} 2 \bullet \bullet \bullet \pi$ indol $^{1}$ & 0.0033 & -0.0023 & & $\mathrm{BCP}(3,-1) \mathrm{O} 1 \mathrm{H} \bullet \bullet \bullet \pi$ indol & 0.0097 & -0.0066 \\
\hline & $\operatorname{BCP}(3,-1) \mathrm{NH} 1 \bullet \bullet \pi$ indol $^{2}$ & 0.0063 & -0.0045 & & $\operatorname{RCP}(3,+1)$ & \multirow[t]{4}{*}{0.0031} & \multirow[t]{4}{*}{-0.0031} \\
\hline & $\mathrm{BCP}(3,-1) \mathrm{C}-\mathrm{H} 2 \bullet \bullet \bullet \pi$ indol $^{2}$ & 0.0034 & -0.0027 & & & & \\
\hline & $\operatorname{RCP}(3,+1)^{1}$ & 0.0031 & -0.0025 & & & & \\
\hline & $\operatorname{RCP}(3,+1)^{2}$ & 0.0034 & -0.0028 & & & & \\
\hline
\end{tabular}

$\rho=$ electron density (e/a.u. $\left.{ }^{3}\right) ; \nabla^{2} \rho=$ Laplacian of density; ${ }^{1}$ and ${ }^{2}$ Indole ring of indolylic moiety.

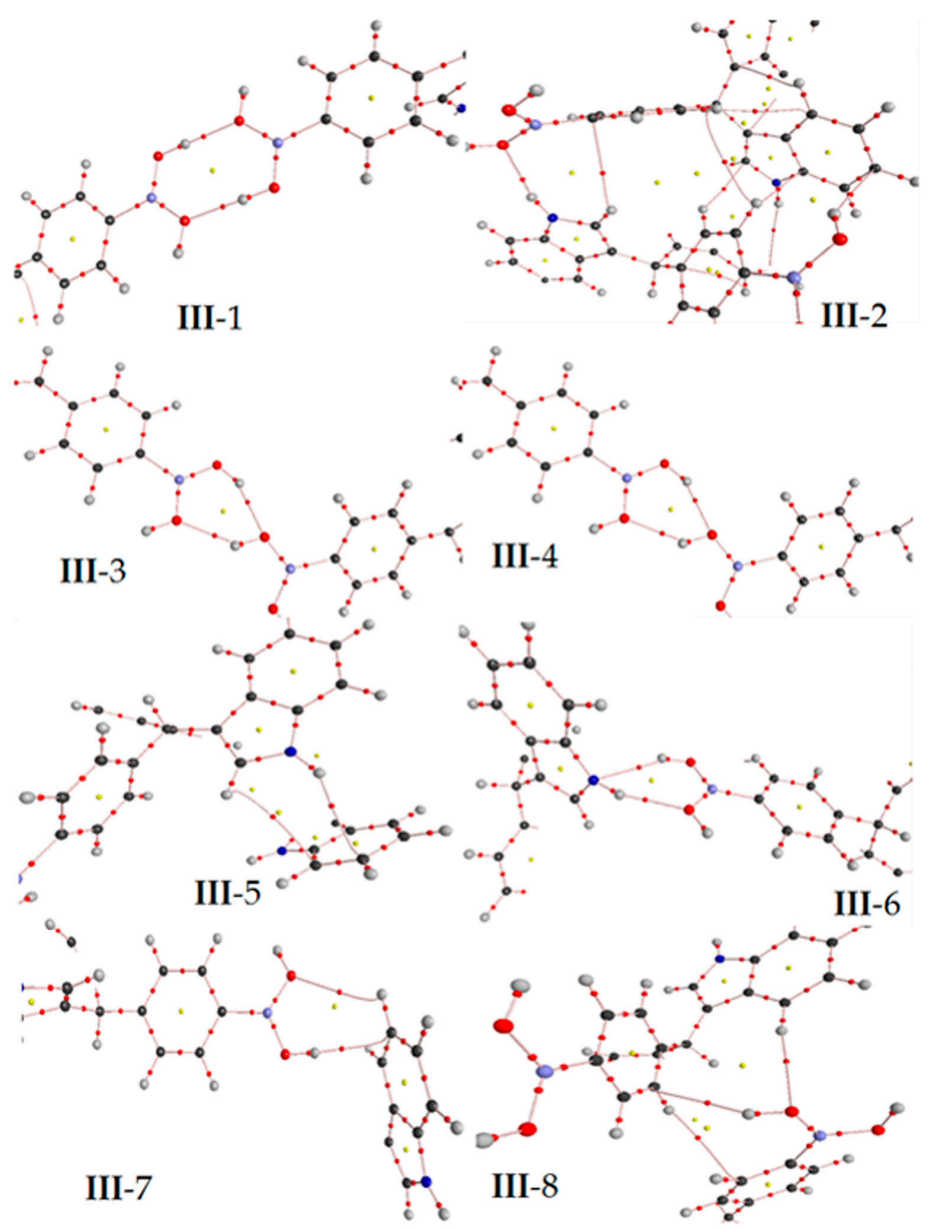

Figure 6. In the target molecule (ct-III) the bond critical points $(3,-1)$ is marked in red small points and ring critical points $(3,+1)$ are presented as yellow points. The gray, blue, pink, red and white spheres are for carbon, nitrogen, boron, oxygen and hydrogen atoms respectively. 


\subsubsection{Spectroscopic Properties}

The theoretical calculations for the vibrational modes in infrared spectroscopy and the chemical shifts in nuclear magnetic resonance were performed for the most stable conformer of the studied molecules (cis-trans). The obtained data were compared with the corresponding experimental values in order to make a detailed analysis of both the vibrational modes and the respective shielding or deshielding phenomena.

\section{Infrared Spectra}

The infrared spectra calculations were made for a free molecule in the gas phase, while the experiments were performed for solid samples considering the use of $\mathrm{KBr}$ to prepare a pellet. Each target molecule I-III consists of 47 atoms, with 135 normal vibrational modes. These normal vibrations are distributed 91 in-plane and 44 out of plane. All the vibrations were active in the IR absorption spectrum. The selected wavenumbers data of the molecules of infrared theoretical and experimental were summarized in Table 8; additionally, the theoretical and experimental IR spectra are displayed in Figure 7.
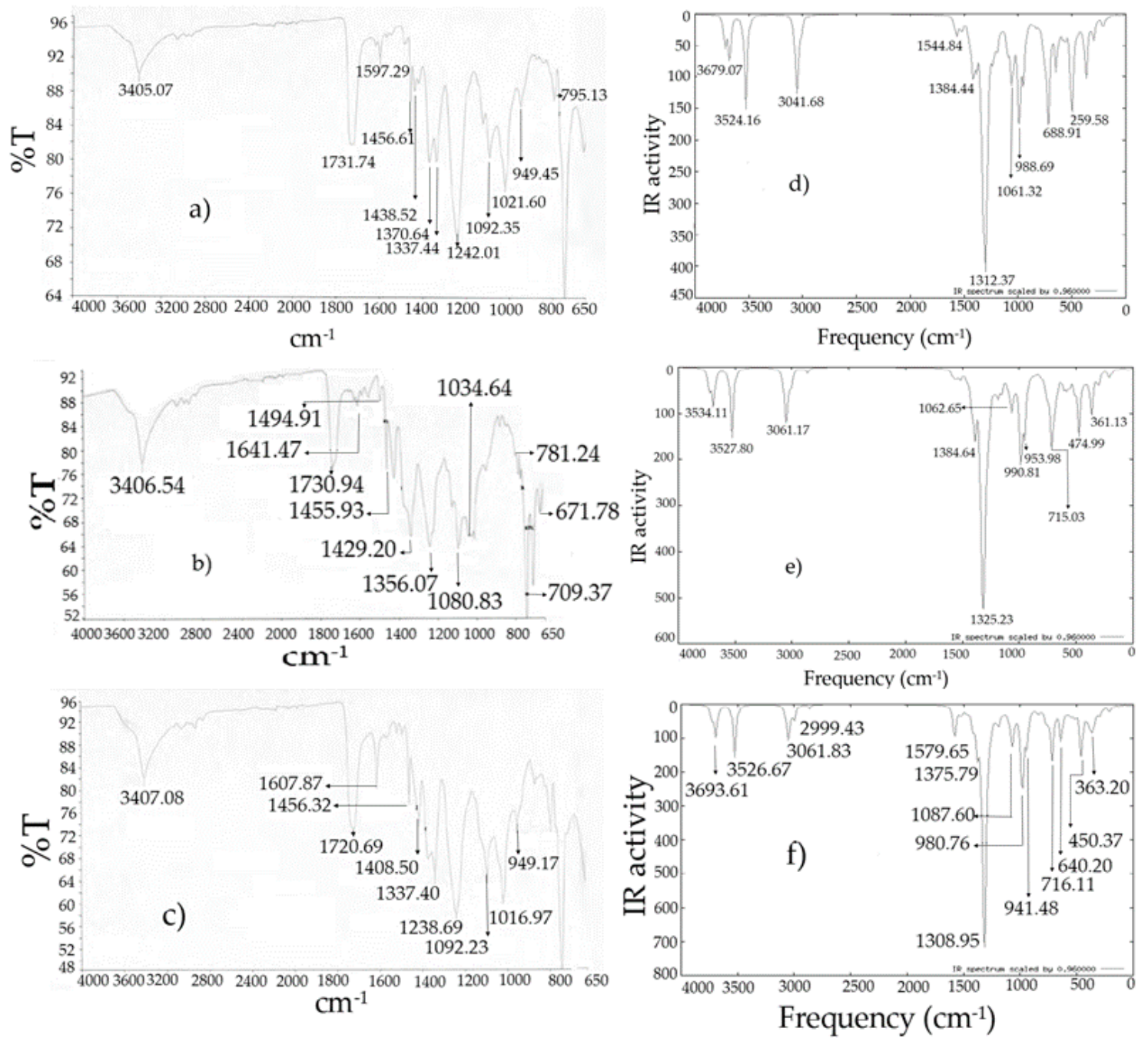

Figure 7. Infrared spectra: (a) I experimental [10]; (b) II experimental [10]; (c) III experimental [10]; (d) I theoretical; (e) II theoretical; (f) III theoretical. 
Table 8. Experimental and theoretical infrared frequencies for the conformer $c t$ to I-III and their approximate mode description.

\begin{tabular}{|c|c|c|c|c|c|c|c|c|c|c|c|c|}
\hline \multicolumn{3}{|c|}{ Experimental Frequencies } & \multicolumn{9}{|c|}{ Theoretically Results } & \multirow{3}{*}{ Mode Descriptions } \\
\hline \multirow{2}{*}{$\mathbf{I}$} & \multirow{2}{*}{ II } & \multirow{2}{*}{ III } & \multicolumn{3}{|c|}{$c t$-I } & \multicolumn{3}{|c|}{$c t$-II } & \multicolumn{3}{|c|}{$c t$-III } & \\
\hline & & & F & $S^{a}$ & $\mathrm{~S}^{\mathrm{b}}$ & F & $\mathrm{S}^{\mathrm{a}}$ & $\mathrm{S}^{\mathbf{b}}$ & F & $\mathrm{S}^{\mathrm{a}}$ & $\mathrm{S}^{\mathbf{b}}$ & \\
\hline \multirow{5}{*}{3405.1} & \multirow{5}{*}{3403.5} & \multirow{5}{*}{3407.1} & 3875.5 & 3720.5 & 3712.7 & 3881.4 & 3726.1 & 3718.3 & 3882.9 & 3727.6 & 3719.8 & $v \mathrm{O} 2 \mathrm{H}$ \\
\hline & & & 3832.4 & 3679.1 & 3671.4 & 3845.5 & 3691.7 & 3684.0 & 3847.5 & 3693,6 & 3685.9 & $v \mathrm{O} 1 \mathrm{H}$ \\
\hline & & & 3674.9 & 3527.9 & 3520.6 & 3674.8 & 3527.8 & 3520.4 & 3674.1 & 3527.2 & 3519.8 & $v N 1^{\prime} \mathrm{H}$ \\
\hline & & & 3674.1 & 3527.2 & 3519.8 & 3674.4 & 3527.5 & 3520.1 & 3673.6 & 3526.7 & 3519.3 & $v \mathrm{~N} 1 \mathrm{H}$ \\
\hline & & & 3189.0 & 3061.5 & 3055.1 & 3188.7 & 3061.2 & 3054.8 & 3189.4 & 3061.8 & 3055.5 & $v_{s} \mathrm{C}_{4} \mathrm{H}+v_{s} \mathrm{C}_{5} \mathrm{H}+v_{s} \mathrm{C}_{6} \mathrm{H}+v_{s} \mathrm{C}_{7} \mathrm{H}$ \\
\hline \multirow{2}{*}{3043.0} & \multirow{2}{*}{3077.9} & \multirow{2}{*}{3080.0} & 3188.7 & 3061.2 & 3054.8 & 3188.1 & 3060.6 & 3054.2 & 3189.1 & 3061.5 & 3055.2 & $v s \mathrm{C}_{4^{\prime}} \mathrm{H}+v \mathrm{sC}_{5^{\prime}} \mathrm{H}+v_{s} \mathrm{C}_{6^{\prime}} \mathrm{H}+v s \mathrm{C}_{7^{\prime}} \mathrm{H}$ \\
\hline & & & 3186.3 & 3058.9 & 3052.5 & 3182.9 & 3055,5 & 3049.2 & 3182.8 & 3055.5 & 3049.1 & $v s \mathrm{C}_{16} \mathrm{H}+v \mathrm{sC}_{15}+v s \mathrm{C}_{13}+v \mathrm{sC}_{12}$ \\
\hline \multirow{2}{*}{2949.5} & \multirow{2}{*}{3000.0} & \multirow{2}{*}{2991.5} & 3179.9 & 3052.7 & 3046.3 & 3178.8 & 3051.7 & 3045.3 & 3179.7 & 3052.5 & 3046.2 & $\operatorname{vas}_{4} \mathrm{H}+\operatorname{vas}_{6} \mathrm{H}+$ vas $_{7} \mathrm{H}$ \\
\hline & & & 3179.2 & 3052.1 & 3045.7 & 3177.8 & 3050.7 & 3044.3 & 3178.8 & 3051.6 & 3045.3 & vas $_{4^{\prime}} \mathrm{H}+$ vas $_{6^{\prime}} \cdot \mathrm{H}+$ vas $_{7^{\prime}} \mathrm{H}$ \\
\hline \multirow{2}{*}{2885.9} & \multirow{2}{*}{2962.7} & \multirow{2}{*}{2943.6} & 3177.5 & 3050.4 & 3044.1 & 3176.1 & 3049,0 & 3042.7 & 3177.7 & 3050.5 & 3044.2 & vas $\mathrm{C}_{16}+$ vas $\mathrm{C}_{14}+$ vas $\mathrm{C}_{15}+$ vas $_{13}$ \\
\hline & & & 1656.2 & 1623.1 & 1628.1 & 1656.5 & 1623.3 & 1628.3 & 1656.7 & 1623.6 & 1628.5 & vasIndolyl \\
\hline \multirow{4}{*}{1731.0} & \multirow{4}{*}{1730.9} & \multirow{4}{*}{1720.7} & 1655.6 & 1622.5 & 1627.4 & 1656.0 & 1622.9 & 1627.8 & 1656.1 & 1623.0 & 1628.0 & vasIndolyil' \\
\hline & & & 1634.6 & 1601.9 & 1606.8 & 1637.0 & 1604.2 & 1609.1 & 1645.5 & 1612.6 & 1617.5 & vasbenzene ring \\
\hline & & & 1614.0 & 1581.8 & 1586.6 & 1613.5 & 1581.2 & 1586.1 & 1613.8 & 1581.5 & 1586.4 & vasIndolyl + vasIndolyl' \\
\hline & & & 1612.2 & 1579.9 & 1584.8 & 1611.1 & 1578.9 & 1583.7 & 1611.7 & 1579.4 & 1584.3 & vasIndolyl + vasIndolyl' + vasbenzene ring \\
\hline \multirow[b]{2}{*}{1597.3} & \multirow[b]{2}{*}{1601.7} & \multirow[b]{2}{*}{1607.9} & 1519.9 & 1489.5 & 1494.0 & 1583.9 & 1552.2 & 1557.0 & 1584.3 & 1552.6 & 1557.4 & vasIndolyl + vasIndolyl' $+\delta \mathrm{N}_{1} \mathrm{H}+\delta \mathrm{N}_{1^{\prime}} \mathrm{H}$ \\
\hline & & & 1519.3 & 1488.9 & 1493.4 & 1520.0 & 1489.6 & 1494.2 & 1579.2 & 1547.7 & 1552.4 & sindolyl + vasIndolyl' $+\delta \mathrm{N}_{1} \mathrm{H}+\delta \mathrm{N}_{1^{\prime}} \mathrm{H}+\delta \mathrm{C}_{5} \mathrm{H}+$ \\
\hline \multirow[b]{2}{*}{1456.6} & \multirow[b]{2}{*}{1455.9} & \multirow[b]{2}{*}{1456.3} & 1508.0 & 1477.9 & 1512.6 & 1479.2 & 1449.6 & 1425.0 & 1443.8 & 1415.0 & 1419.3 & $v s \mathrm{C}_{11} \mathrm{C}_{12} \mathrm{C}_{15} \mathrm{C}_{16}+\delta \mathrm{H}_{13} \mathrm{H}_{15}$ \\
\hline & & & 1480.5 & 1450.9 & 1426.1 & 1452.4 & 1423.3 & 1399.2 & 1442.8 & 1414.0 & 1418.3 & $\operatorname{vas}_{8} \mathrm{C}_{9} \mathrm{C}_{4} \mathrm{C}_{5} \mathrm{C}_{6} \mathrm{C}_{7}+\delta \mathrm{H}_{4} \mathrm{H}_{5}$ \\
\hline & & & 1469.4 & 1440.0 & 1415.5 & 1444.3 & 1415.4 & 1391.4 & 1433.1 & 1404.5 & 1408.8 & vas $\mathrm{C}_{11} \mathrm{C}_{12} \mathrm{C}_{13} \mathrm{C}_{14} \mathrm{C}_{15} \mathrm{C}_{16}+\delta \mathrm{H}_{14} \mathrm{H}_{15} \mathrm{H}_{16}$ \\
\hline 1438.6 & 1419.2 & 1408.5 & 1388.9 & 1361.1 & 1337.9 & 1442.3 & 1413.5 & 1389.5 & & & & $\delta$ Indolyl $+\delta$ Indolyl' $+\delta$ benzene ring \\
\hline 1370.6 & & 1392.0 & 1381.9 & 1354.3 & 1331.2 & 1385.9 & 1358.2 & 1362.3 & 1519.5 & 1489.1 & 1493.6 & $\delta$ Indolyl $+\delta$ Indolyl ${ }^{\prime}+\delta$ benzene ring + vasBO1 $+\delta$ oopC10H \\
\hline
\end{tabular}

$\mathrm{S}$ a = Frequencies scaled with correction factors: below of $1700 \mathrm{~cm}^{-1}$ factor of 0.98 and the rest of the frequencies with $0.96 ; \mathrm{S}^{\mathrm{b}}=$ Frequencies scaled with correction factors: in range of $1700-4000 \mathrm{~cm}^{-1}$ with factor of 0.958 , and below with $0.983 ; v=$ stretching; $v$ s = symmetric stretching; $v$ as = asymmetric stretching; $\delta=$ in the plane bending; $\gamma=$ out of plane bending. 
The assignments of the vibrational absorptions were made by comparison between related molecules reported in the literature and those results obtained from the respective theoretical calculations $[1,3,14,15]$. The descriptions of the presented modes were approximated, being convenient to note that some of the vibration were mixed together. Regarding the results, the presence of four bands in the range of $3700-3500 \mathrm{~cm}^{-1}$ were observed for the target molecules (Table 8 and Figure 7), where the two bands at high frequencies correspond to the $\mathrm{OH}$ stretching of the boronic acid group $[1,3,14,15,22]$ and the next bands were attributed to $\mathrm{N}-\mathrm{H}$ stretching of the corresponding indolylic moieties. It is convenient to note, that in the experimental spectra a broad band around $3400 \mathrm{~cm}^{-1}$, was assigned to the mix of the aforementioned bands.

The $\mathrm{C}-\mathrm{H}$ stretching frequencies appeared in the range of $3100-3000 \mathrm{~cm}^{-1}$ corresponding to an aromatic compound and in the range of $2850-3000 \mathrm{~cm}^{-1}$, for an aliphatic molecule. In this sense, the symmetrical stretching of the aromatic indolylic and benzene rings were observed in the range $3060-3050 \mathrm{~cm}^{-1}$, the bands from 3050 to $3040 \mathrm{~cm}^{-1}$ of C-H asymmetrical stretching of the indolyl group, and of the benzene ring hydrogens. In the experimental spectra the symmetrical and asymmetrical stretching bands were observed in the ranges of 3100-3000, 3000-2900 and 2900-2800 $\mathrm{cm}^{-1}$, respectively. The theoretically scaled frequency and the experimental data were in agreement $[27,28]$.

The $\mathrm{C}=\mathrm{C}$ stretching and bending in aromatic compounds are usually found between $1620-1680 \mathrm{~cm}^{-1}$ and $1500-1700 \mathrm{~cm}^{-1}$, respectively. In the target compounds, intense bands around $1700 \mathrm{~cm}^{-1}$ were obtained in the experimental procedure and in the computed values these were perceived in the range of $1630-1580 \mathrm{~cm}^{-1}$; these correspond to the symmetrical stretching of the indolylic moiety and the benzene ring $[27,28]$. An experimental band around $1600 \mathrm{~cm}^{-1}$ was assigned to the asymmetrical stretch of the indole and the benzene ring, in addition to the bending of $\mathrm{C}-\mathrm{H}$ and $\mathrm{N}-\mathrm{H}$ bonds, that were correlated with the theoretical values at $1580-1490 \mathrm{~cm}^{-1}$.

The B-O asymmetric stretching band of phenylboronic acid occurs around $1390-1330 \mathrm{~cm}^{-1}[14,21,29]$, and the corresponding experimental infrared spectrum showed a band at 1336-1337 for the diindolylmethane phenylboronic acid hybrids. The calculated band appeared in the range of $1360-1330 \mathrm{~cm}^{-1}$, in other words, the theoretical and experimental values are in accordance. The B-C stretching band according to the literature is found in the range of 1080 and $1110 \mathrm{~cm}^{-1}$ or up to $1300 \mathrm{~cm}^{-1}[3,14,15,27-29]$. For the studied molecules, the experimental bands were found close to $1090 \mathrm{~cm}^{-1}$ meanwhile the calculated values were around $1100-1070 \mathrm{~cm}^{-1}$. Finally, the B-OH bending band was observed in the range of $1039-1017 \mathrm{~cm}^{-1}$ while in the target molecules it was in the theoretical range of 1030 and $960 \mathrm{~cm}^{-1}$. In general, the mentioned values agree.

\section{NMR Spectroscopy}

An interesting outcome was obtained from the corresponding theoretical study of the Nuclear Magnetic Resonance (NMR) chemical shifts for ${ }^{1} \mathrm{H},{ }^{13} \mathrm{C}$ and ${ }^{11} \mathrm{~B}$, both in gas phase and acetone solution. It should be mentioned that the corresponding experimental values of the chemical shifts for ${ }^{1} \mathrm{H}$ and ${ }^{13} \mathrm{C}$ have been previously reported by our research group [12], and these values were correlated with those calculated by DFT at the B3LYP level using the 6-311++G(d,p) basis set and the GIAO method (Figure 8).

Thus, the GIAO methodology and Tomasi's polarizable continuum model (PCM) were used, considering the agreement among experimental and theoretical data observed in previous works [30, 31]. However, in this case, the linear regression analysis of the data set of ${ }^{1} \mathrm{H}-\mathrm{NMR}$ shifts with the gas phase data, provided a regression coefficient of 0.1047 , indicating a disagreement in the theoretical and experimental data. The review of the calculated values showed greater variations in the hydrogens of the boronic acid group and in the nitrogen in the indolyl groups. These differences were attributed to the hydrogens located on the periphery of the molecule, more susceptible to intermolecular interactions, resulting in a deviation from the theoretical values.

The computational study was carried out using the solvent effect of acetone in explicit and implicit modes. In a first approach, the solvent effect was studied using the self-consistent reaction 
field (SCRF) method and considering Tomasi's polarizable continuum model (PCM) at the same theory level aforementioned. The chemical shift results with this procedure also disagreed with the obtained experimental results in the linear regression analysis, providing a regression coefficient of 0.105 , which is slightly different from the gas phase value, overlapping the line with the gas phase line. In addition, explicit interactions between the solvent, in this case acetone, with the hydrogen of the boronic acid group and the nitrogen atom of the indolyl groups, were established and their chemical shifts consequently calculated. The results were similar to the experimental values, giving a regression coefficient of 0.8224 , confirming the explicit interactions with the solvent. Finally, the chemical shifts were also determined using the mix of PCM and explicit interaction obtaining a regression coefficient of 0.8322 , that means a slightly increase in the experimental value approximation. The equation used to describe the last fit was $\delta \mathrm{H}_{\text {theo }}=1.159 \delta \mathrm{H}_{\text {exp }}-0.726 \mathrm{ppm}$, where $\delta \mathrm{H}_{\text {theo }}$ is a chemical shift predicted on the basis of the experimental values $\delta \mathrm{H}_{\text {exp }}$. The slope and intercept showed a standard deviation of 0.089 and 0.660 , respectively.
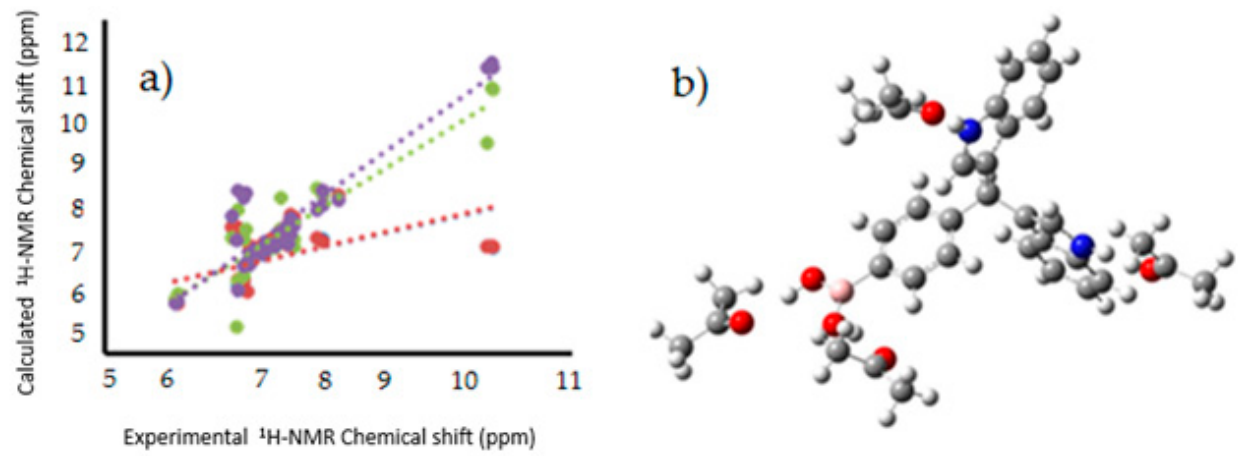

Figure 8. (a) Linear regression between experimental [12], and calculated ${ }^{1} \mathrm{H}-\mathrm{NMR}$ chemical shifts for the target molecules in PCM (Red), explicit interaction (Green), PCM and explicit interaction (purple); (b) Model of explicit interaction for III with four acetone molecules. The gray, blue, pink, red and white spheres are for carbon, nitrogen, boron, oxygen and hydrogen atoms respectively.

A similar analysis was made for the theoretical and experimental chemical shifts obtained for ${ }^{13} \mathrm{C}$ - and ${ }^{11} \mathrm{~B}-\mathrm{NMR}$, and the corresponding scheme is shown in Figure 9. In contrast with the ${ }^{1} \mathrm{H}-\mathrm{NMR}$ calculations, the gas phase computed chemical shifts for ${ }^{13} \mathrm{C}$ and ${ }^{11} \mathrm{~B}$ agreed with the experimental values, with regression coefficients of 0.979 and 0.996 , respectively. This concordance, in contrast with the ${ }^{1} \mathrm{H}$ predictions is a consequence of the lesser susceptibility of the boron and carbon atoms to intermolecular interactions in comparison with the hydrogen ones.
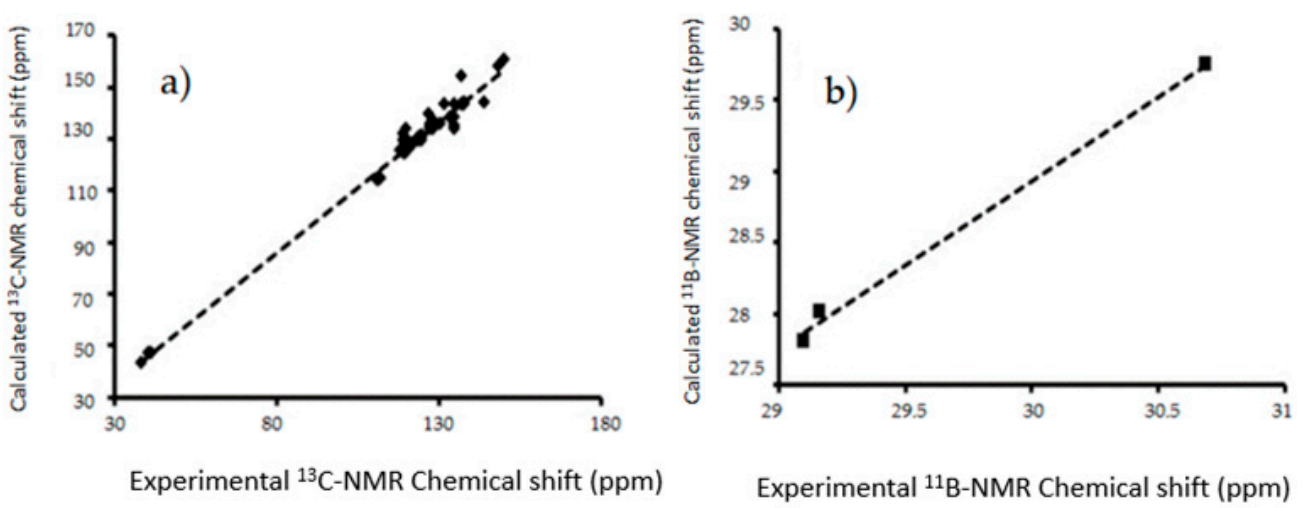

Figure 9. The linear regressions between experimental and B3LYP/6-311++G $(d, p)$ calculated (a) ${ }^{13} \mathrm{C}-\mathrm{NMR}$ chemical shifts for in gas phase (b) ${ }^{11} \mathrm{~B}-\mathrm{NMR}$ chemical shifts in gas phase $\mathbf{I}-\mathrm{III}$. 
The equations to describe the fit of ${ }^{13} \mathrm{C}$ and ${ }^{11} \mathrm{~B}$ were $\delta \mathrm{C}_{\text {theo }}=1.0148 \delta \mathrm{C}_{\exp }+4.7488 \mathrm{ppm}$, with a slope and intercept standard deviation of 0.0187 and 2.3004 , respectively and in the case of ${ }^{11} \mathrm{~B}$, $\delta \mathrm{B}_{\text {theo }}=1.1803 \delta \mathrm{B}_{\exp }-5.8856 \mathrm{ppm}$, and a slope and intercept standard deviation of 0.0747 and 2.1786 , respectively. In other words, the values of the regression coefficients reflected a good description of the experimental chemical shifts by the selected method, both at a theory and the basis set level.

\subsection{Reactivity Parameters}

The reactivity parameters of the title molecules-hardness $(\eta)$, chemical potential $(\mu)$ and electrophilicity $(\omega)$-were calculated considering the electronic affinity $(E A)$ values and their ionization energy $(I)$. The cation and anion energies of the studied molecules were calculated at the same level and were used for the $E A$ and $I$. The obtained results as well as the corresponding previously evaluated biological activity [12] are summarized in Table 9. Taking into account the respective values of the electronic affinity, I showed the greater value in comparison with the minor value of III. This behavior was explained considering the stability of III in its neutral form; furthermore, this result could be related with the corresponding lesser biological activity. On the other hand, the ionization energy, the hardness, in addition to the chemical potential, nucleophilicity and electrophilicity followed a behavior from major to minor value in the order of III $>$ II $>$ I. This outcome was contrasted with the percentage of growth inhibition in some cell lines and some trends were found. For example, III showed the bigger hardness values agreeing with the lesser reactivity, while marked and lower activity was observed in all the cell lines.

It is convenient to note that the high reactivity of $\mathbf{I}$ could cause an interaction with some molecules present in the cytoplasm, e.g., sugars, and not reactions with the target receptors or proteins [6,32,33], for the cytotoxic effect. In addition, the activities of I-III in the PC-3 cell line were inversely proportional to their reactivity values, being I the most active.

Table 9. Reactivity properties of objective molecules and the corresponding relationship with their biological effect.

\begin{tabular}{ccccc}
\hline Property & & $c t$-I & $c t$-II & $c t$-III \\
\hline \multirow{3}{*}{ Energy (Hartree) } & Neutral & -1173.13344187 & -1173.13778578 & -1173.13846019 \\
& Negative & -1173.12670369 & -1173.13148373 & -1173.13365972 \\
& Positive & -1172.88003603 & -1172.88224063 & -1172.87999701 \\
\hline & $E A$ & -0.18 & -0.17 & -0.13 \\
Reactivity (Ev) & $\mathrm{I}$ & 6.90 & 6.95 & 7.03 \\
& $\mu$ & -6.80 & -6.87 & -6.97 \\
& $\eta$ & 3.54 & 3.56 & 3.58 \\
& $\omega$ & 6.54 & 6.62 & 6.78 \\
& $N$ & -6.90 & -6.95 & -7.03 \\
\hline & U251 & 36 & 49 & 7.59 \\
& PC-3 & 62.79 & 50.63 & 26.85 \\
Biological activity (\%) & K562 & 0.00 & 19.42 & 0.00 \\
& HCT-15 & 47.59 & 59.13 & 48.96 \\
& MCF-7 & 60.27 & 81.81 & 11.09 \\
\hline
\end{tabular}

Neutral $=$ neutral specie; Positive $=$ cationic specie; Negative $=$ anionic specie; $E A=$ electronic affinity $I=$ ionization energy; $\mu$ = chemical potential; $\eta=$ hardness; $\omega=$ electrophilicity; $N=$ nucleophilicity index [34]; U251 = glia of central nerve system cancer cells; PC-3 = prostate cancer cells; K562 = leukemia cancer cells; HCT-15 = colon cancer cells; MCF-7 = breast; SKLU-1 = lung cancer cells.

Finally, the activity in the rest of the cells lines followed the trend of the cationic species stability in which II showed the higher activity. It is important to note that this correlation is a worthy subject of study for subsequent works using biological tests and in silico studies. 


\subsection{Metabolic Products as Bioactive Molecules}

It is appropriate to highlight the fact that the target molecules are promising compounds with possible uses as drugs [12]. This study establishes plausible degradation pathways for the phase 1 and 2 human metabolism, that can be predicted using the program metaprind2D [35-37]. The corresponding results are displayed in Figure 10 for III and II, while the suggested metabolism of I is shown in Figure 11. It is also convenient to note that I and III correspond to the more and less reactive molecules, respectively, a status reflected in the number of metabolites predicted. In Figures 10 and 11 , the corresponding colors used to highlight atoms indicate the normalized occurrence ratio (NOR).
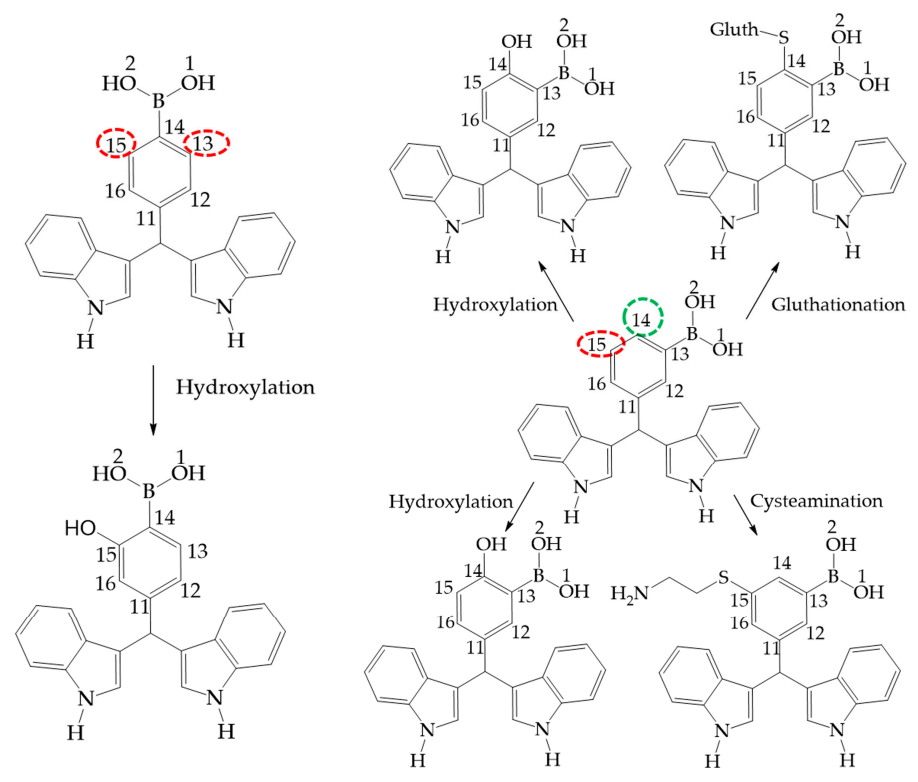

Figure 10. Phase 1 metabolic pathways of III and II. The red color indicates high values of NOR, from 0.66 to 1 . The green color indicates a NOR value range of 0.15 to 0.33 .

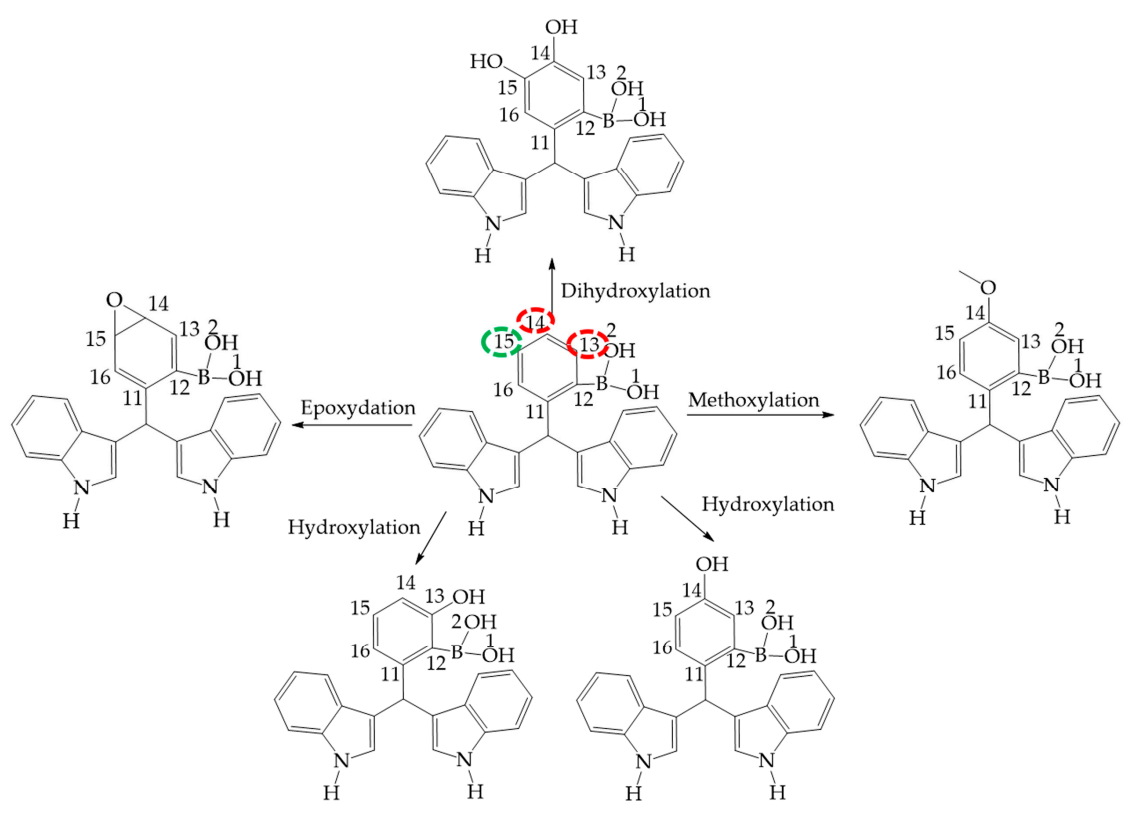

Figure 11. Phase 1 metabolic pathway of $\mathbf{I}$. The red color indicates high values of NOR, from 0.66 to 1 . The green color indicates a NOR value range of 0.15 to 0.33 . 
A high NOR indicates a more frequently reported site or metabolism in the metabolite database. The red color indicates high values of NOR, from 0.66 to 1 ; the orange color designates values between 0.33 to 0.66 , the green color indicates a NOR value range of 0.15 to 0.33 , the white color, range values of 0.00 to 0.15 and finally grey denotes lack of data. It is important to highlight that in the studied molecules only red and green colors were found. Moreover, the number of metabolites predicted was correlated with the local reactivity parameters as the Fukui $\left(f^{-}\right)$and Parr indexes, the local nucleophilicity and electrophilicity $\left(\mathrm{P}^{-}, \mathrm{P}^{+}, N_{\mathrm{k}}, \omega_{\mathrm{k}}\right)[34,38]$, which are displayed in Table 10.

Table 10. Selected local reactivity parameters of I-III.

\begin{tabular}{|c|c|c|c|c|c|c|c|c|c|c|c|c|c|c|c|}
\hline \multirow{2}{*}{ Atom } & \multicolumn{3}{|c|}{$f^{-}$} & \multicolumn{3}{|c|}{$P^{-}{ }_{k}$} & \multicolumn{3}{|c|}{$P_{k}^{+}$} & \multicolumn{3}{|c|}{$N_{\mathrm{k}}$} & \multicolumn{3}{|c|}{$\omega_{k}$} \\
\hline & I & II & III & I & II & III & I & II & III & I & II & III & I & II & III \\
\hline C11 & 0.030 & 0.020 & 0.060 & 0.010 & 0.030 & 0.010 & 0.020 & -0.040 & 0.010 & -0.140 & 0.280 & -0.070 & 0.050 & 0.220 & 0.030 \\
\hline $\mathrm{C} 12$ & -0.010 & 0.080 & 0.010 & 0.000 & -0.010 & 0.000 & 0.010 & 0.010 & 0.000 & -0.030 & -0.050 & 0.020 & 0.010 & -0.070 & 0.030 \\
\hline $\mathrm{C} 13$ & -0.010 & -0.170 & 0.010 & -0.010 & 0.010 & 0.000 & 0.020 & 0.000 & 0.000 & -0.140 & -0.030 & -0.010 & -0.050 & 0.040 & 0.020 \\
\hline C14 & -0.030 & 0.030 & 0.070 & 0.010 & 0.010 & 0.000 & 0.030 & 0.000 & -0.060 & -0.210 & -0.010 & 0.390 & 0.040 & 0.090 & -0.030 \\
\hline C15 & -0.010 & 0.230 & -0.030 & 0.020 & -0.010 & -0.010 & 0.040 & -0.030 & 0.000 & -0.280 & 0.210 & -0.010 & 0.130 & -0.030 & -0.040 \\
\hline $\mathrm{C} 16$ & 0.000 & -0.040 & 0.020 & 0.040 & 0.010 & 0.000 & 0.020 & 0.060 & -0.010 & -0.140 & -0.420 & 0.040 & 0.260 & 0.030 & -0.010 \\
\hline
\end{tabular}

It is noted that the reactive centers indicated by the metaprind2D program correspond to the atoms in the phenylboronic acid moiety with the less steric effect and with better values of local reactivity. In case of II, the biggest value of electrophilicity and less steric hindrance is found at C14 $\left(\omega_{\mathrm{k}}=0.090\right)$ being this an electrophilic center; in this sense C15 has a big value of nucleophilicity $\left(N_{\mathrm{k}}=0.210\right)$; in that sense C15 in III had values of 0.030 corresponds to the most electrophilic center with less steric effect $\left(N_{\mathrm{k}}=0.030\right)$.

The predicted metabolites correspond to the reaction of III and II with reactive oxygen species (ROS) indicating antioxidant character [6,39,40]; Complementarily, Figure 11 shows the metabolism products of $\mathbf{I}$. The reactive sites also agree with the most deactivated nucleophilic centers $(\mathrm{C} 14=-0.21$ and C15 $=-0.280)$ and the best electrophilic centers without steric hindrance $(\mathrm{C} 14=0.040$ and $\mathrm{C} 15=0.130$ ) showing the same behavior in the hydroxylated derivatives production. However, these results predicted the possibility of elimination by the action of glutathione $S$-transferase, a detoxification enzyme [41], in addition to the reaction of II with cysteamine.

\section{Methods}

\subsection{Calculational Methods}

\subsubsection{Density Functional Theory}

The molecular mechanics search for conformers of the diindolylmethane phenylboronic acids (I: ortho, II: meta, III: para) and their intermolecular interactions [13], were determined using the PC Spartan'06 program [42]. The corresponding molecular geometry and all the calculations were performed using the Gaussian 09 program [43]. The Becke's three-parameter hybrid density functional, B3LYP $[44,45]$, was used to calculate geometry optimization, electronic and spectroscopic properties with the 6-311++G(d,p) basis set [46-49]. The optimization was carried out using the Berny analytical gradient optimization methods [50-52].The first step of the calculations also yielded the distribution of atomic net charges.

\subsubsection{Atoms in Molecules}

The intra and intermolecular H bonding (HB) interactions were analyzed using Bader's topological analyses based on atoms in molecules (AIM) theory $[17,18,53]$. This type of analysis provides critical points of $\rho(r)$ and it's Laplacian, $\nabla^{2} \rho(r)$. The critical points of $\rho(r)$, which present two negative curvatures and one positive curvature, identify the bonds in the molecule and will be denoted hereafter as bond critical points (BCPs). The critical points with one negative and two positive curvatures are 
associated with the existence of a ring structure and will be denoted as ring critical points (RCPs). The values of $\rho(r)$ and $\nabla^{2} \rho(r)$ at these points provide quantitative information on the strength and nature of the bonding and the characteristics of the ring. The Laplacian of the electronic charge density, identifies regions of space where $\rho(r)$ is locally concentrated, $\nabla^{2} \rho(r)>0$, or depleted, $\nabla^{2} \rho(r)<0$. In general, negative values of $\nabla^{2} \rho(r)$ are typical of covalent interactions, whereas interactions between closed-shell systems are characterized by positive values of $\nabla^{2} \rho(r)$. Some topological criteria of the existence of $\mathrm{HB}$ have been proposed [54-56]. The following are the most common criteria applied to study HB interactions:

i. $\quad$ A BCP must be located within the $\mathrm{H} \bullet \bullet \bullet$ A contact region, which topologically proves an increase in the density and consequence the existence of $\mathrm{HB}$;

ii. The value of the electron density of the $\mathrm{BCP}$ arising from the $\mathrm{H} \bullet \bullet \bullet \mathrm{A}$ interaction, which should range between 0.002 and 0.040 a.u.;

iii. The value of the corresponding Laplacian, which should range from -0.139 to -0.024 a.u.;

The AIM analyses were performed with the AIM2000 computer algorithm [57].

\subsubsection{Vibrational Analysis}

Density functional theory calculations are reported to provide excellent vibrational frequencies of organic compounds, if the calculated frequencies are scaled to compensate for the approximate treatment of electronic correlation, for basis set deficiencies and for the anharmonicity [58-61].

Rauhut and Pulay [58] calculated the vibrational spectra of thirty-one molecules by using B3LYP methods with 6-31G(d) basis set, which can be used in order to eliminate the uncertainties in the fundamental assignments in infrared spectra. Consequently in this work, by using the DFT (B3LYP/6-311++G $(\mathrm{d}, \mathrm{p})$ method, the respective vibrational frequencies were calculated, and the molecular energy was differentiated twice with respect to the Cartesian coordinates of the diindolylmethane atoms in the ground state. The outcome represents the vibrational force constants of the molecule and the vibrational frequencies of vibrational modes and the integrated intensities of infrared bands. Therefore, these calculations are valuable to provide insight into the vibrational spectrum. According to the quantum chemical literature [62], the B3LYP functional yields a good description of harmonic vibrational wavenumbers for small and medium sized molecules; the calculations refer to the isolated molecules while the vibrational spectra are recorded mostly in condensed phase. However, the quantum chemical results differ from the measured ones, consequently these calculations were scaled; in this sense, the thermal contributions to the vibrational energy were scaled by 0.963 [63].

\subsubsection{Chemical Shift Calculations}

The calculations were performed to determine the ${ }^{1} \mathrm{H}-,{ }^{13} \mathrm{C}$ - and ${ }^{11} \mathrm{~B}-\mathrm{NMR}$ chemical shifts by the GIAO method [64,65], employing the B3LYP functional with the 6-311++G(d,p) basis set and using as references tetramethylsilane for ${ }^{1} \mathrm{H}$ or ${ }^{13} \mathrm{C}$, and boron trifluoride for ${ }^{11} \mathrm{~B}$. The solvent effect in the chemical shift was also calculated by using the self-consistent reaction field (SCRF) method and considering Tomasi's polarizable continuum model (PCM) at the same theory level, using acetone as the medium. Finally, explicit interaction with the solvent was computed, in order to obtain the corresponding chemical shifts values [66,67].

\subsubsection{Reactivity Descriptors}

The chemical potential $(\mu)$, hardness $(\eta)$, nucleophilicity $(N)$, electrophilicity $(\omega)$, Fukui fuction $\left(f^{-}\right)$,were calculated by the respectively equation [68-72]:

$$
\mu=-\frac{(I+E A)}{2}
$$




$$
\begin{gathered}
n=\frac{I-E A}{2} \\
\omega=\frac{\mu^{2}}{2 n} \\
N=-I \\
f_{k}^{-}=q_{k}(N)-q_{k}(N-1)
\end{gathered}
$$

where $I$ is the ionization energy and $E A$ electron affinity, this values were calculated from the energies of the neutral, cationic and anionic forms of I-III at the same theory level. Additionnally, Parr functions $\left(P^{-}{ }_{\mathrm{k}}, P^{+}{ }_{\mathrm{k}}\right)$, local nucleophilicity $\left(N_{\mathrm{k}}\right)$ and local electrophilicity $\left(\omega_{\mathrm{k}}\right)$ indices of the phenilboronic carbons atoms were determined $[34,38,73]$.

$$
P_{k}^{-}=\rho_{k}^{r c}
$$

where $\rho$ is the spin atomic density of cation radical specie.

$$
P_{k}^{+}=\rho_{k}^{r a}
$$

where $\rho$ is the spin atomic density of anion radical specie.

$$
\begin{aligned}
& N_{k}=N P_{k}^{-} \\
& \omega_{k}=\omega P_{k}^{+}
\end{aligned}
$$

\subsubsection{Metabolism Prediction}

The human metabolism of the studied molecules was studied using MetaPrint2D-Reaction, a xenobiotic metabolism prediction software based on data-mining and statistical analysis of known metabolic transformations reported in the scientific literature [35,37,74-78]. The corresponding results are displayed as circular coloured marks that predict the reactions at that site and the reaction types, to show the metabolite formed. The colour of the mark in the atoms indicates its normalized occurrence ratio (NOR). A high NOR indicates a more frequently reported metabolism site in the metabolite database.

\subsection{Experimental Methods}

Experimental Procedure for the Synthesis of Hybrid DIMs-Phenyl Boronic Acids Previously Reported in the paper: A Green Approach to the Production of Hybrid DiindolylmethanePhenylboronic Acids via a 3MCR: Promising Antineoplasic Molecules [12].

\section{Conclusions}

The three regioisomers of some hybrid diindolylmethane-phenylboronic acids were studied by means of DFT. The structural, electronic and spectroscopic properties concurred with the experimental data reported for similar compounds. Furthermore, the existence of eight dimeric structures was proposed, some of them, comparable with experimental X-ray data from other works. In addition, the effect of the interactions of the target molecules with solvent in the ${ }^{1} \mathrm{H}-\mathrm{NMR}$ chemical shifts was evaluated and the results agree with the experimental data. The reactivity properties were determined for the studied compounds and correlated with the biological activity of these molecules. Finally, an approach to the metabolism of the evaluated compounds in humans was presented and correlated with the reactivity properties. 
Acknowledgments: To Dirección General de Cómputo y de Tecnologías de Información y Comunicación: MIZTLI-DGTIC-UNAM: LANDCAD-UNAM-DGTIC-165. Also acknowledges CONACYT for the Ph.D. scholarships A.J.F.-M. and R.G.E.-G. (259603 and 24992). The authors also acknowledge the technical assistance of Moisés Hernández Duarte.

Author Contributions: A.J.F.-M., R.G.E.-G and M.I.N.-V. carried out theoretical calculations and analyzed the data. G.A.A.-R, M.O.N.-C and R.M.-R. took part in discussion and helped in editing the manuscript. All authors read and approved the final version of the document.

Conflicts of Interest: The authors declare no conflict of interest.

\section{References}

1. Kurt, M.; Sertbakan, T.R.; Özduran, M. An experimental and theoretical study of molecular structure and vibrational spectra of 3- and 4-pyridineboronic acid molecules by density functional theory calculations. Spectrochim. Acta Part. A Mol. Biomol. Spectrosc. 2008, 70, 664-673. [CrossRef] [PubMed]

2. Velasco, B.; Trujillo-Ferrara, J.G.; Castillo, L.H.F.; Miranda, R.; Sánchez-Torres, L.E. In vitro apoptotic activity of 2,2-diphenyl-1,3,2-oxazaborolidin-5-ones in L5178Y cells. Life Sci. 2007, 80, 1007-1013. [CrossRef] [PubMed]

3. Alver, Ö.; Parlak, C. DFT, FT-Raman, FT-IR, liquid and solid state NMR studies of 2,6-dimethoxyphenylboronic acid. Vib. Spectrosc. 2010, 54, 1-9. [CrossRef]

4. Barth, R.F.; Soloway, A.H.; Fairchild, R.G. Boron Neutron Capture Therapy of Cancer1. Cancer Res. 1990, 50, 1061-1070. [PubMed]

5. Chen, X.; Liang, G.; Whitmire, D.; Bowen, J.P. Ab initio and molecular mechanics (MM3) calculations on alkyl- and arylboronic acids. J. Phys. Org. Chem. 1998, 11, 378-386. [CrossRef]

6. Scorei, I.R. Boron Compounds in the Breast Cancer Cells Chemoprevention and Chemotherapy. In Breast Cancer-Current and Alternative Therapeutic Modalities; InTech: Rijeka, Croatia, 2011.

7. Yang, W.; Gao, X.; Wang, B. Boronic acid compounds as potential pharmaceutical agents. Med. Res. Rev. 2003, 23, 346-368. [CrossRef] [PubMed]

8. Wattenberg, L.W.; Loub, W.D. Inhibition of polycyclic aromatic hydrocarbon-induced neoplasia by naturally occurring indoles. Cancer Res. 1978, 38, 1410-1413. [PubMed]

9. Chang, X.; Tou, J.C.; Hong, C.; Kim, H.-A.; Riby, J.E.; Firestone, G.L.; Bjeldanes, L.F. 3,3'-Diindolylmethane inhibits angiogenesis and the growth of transplantable human breast carcinoma in athymic mice. Carcinogenesis 2005, 26, 771-778. [CrossRef] [PubMed]

10. Wiatrak, B.J. Overview of recurrent respiratory papillomatosis. Curr. Opin. Otolaryngol. Head Neck Surg. 2003, 11, 433-441. [CrossRef] [PubMed]

11. Auborn, K.J. Therapy for recurrent respiratory papillomatosis. Antivir. Ther. 2002, 7, 1-10. [PubMed]

12. Zarco Juarez, M.; Martínez, J.O.; Noguez Cordova, O.; Nicolás Vazquez, M.I.; Ramírez-Apan, T.; Pérez Flores, J.; Miranda Ruvalcaba, R.; Arroyo Razo, G.A. A green approach to the production of hybrid diindolylmethane-phenylboronic acids via a 3MCR: Promising antineoplasic molecules. J. Chem. 2013, 2013, 1-9. [CrossRef]

13. Hehre, W.J. A Brief Guide to Molecular Mechanics and Quantum Chemical Calculations; Wavefunction: Irvine, CA, USA, 1998.

14. Kurt, M. An experimental and theoretical study of molecular structure and vibrational spectra of pentafluorophenylboronic acid molecule by density functional theory and ab initio Hartree Fock calculations. J. Mol. Struct. 2008, 874, 159-169. [CrossRef]

15. Erdogdu, Y.; Tahir Güllüoğlu, M.; Kurt, M. DFT, FT-Raman, FT-IR and NMR studies of 2-fluorophenylboronic acid. J. Raman Spectrosc. 2009, 40, 1615-1623. [CrossRef]

16. Glaser, R.; Knotts, N. Coordinate covalent $\mathrm{C} \rightarrow \mathrm{B}$ bonding in phenylborates and latent formation of phenyl anions from phenylboronic acid. J. Phys. Chem. A 2006, 110, 1295-1304. [CrossRef] [PubMed]

17. Bader, R.F.W.; Tang, T.H.; Tal, Y.; Biegler-Koenig, F.W. Molecular structure and its change: Hydrocarbons. J. Am. Chem. Soc. 1982, 104, 940-945. [CrossRef]

18. Bader, R.F.W.; Essén, H. The characterization of atomic interactions. J. Chem. Phys. 1984, 80, $1943-1960$. [CrossRef] 
19. Kumar, G.S.S.; Prabhu, A.A.M.; Seethalaksmi, P.G.; Bhuvanesh, N.; Kumaresan, S. In situ Bronsted-Lowry acid catalyzed syntheses, characterization, single crystal XRD, electronic spectral-, DPPH radical scavenging-, and DNA protection studies of aryl-3,3'-bis (indolyl) methanes. Spectrochim. Acta Part A Mol. Biomol. Spectrosc. 2014, 123, 249-256. [CrossRef] [PubMed]

20. Maciejewska, D.; Wolska, I.; Niemyjska, M.; Żero, P. Structure in solid state of 3,3'-diindolylmethane derivatives, potent cytotoxic agents against human tumor cells, followed X-ray diffraction and 13C CP/MAS NMR analyses. J. Mol. Struct. 2005, 753, 53-60. [CrossRef]

21. Smith, G.T.; Howard, J.A.K.; Wallis, J.D. Characterisation of weak intramolecular interactions in the topology of the experimental charge density of 2,2'-ethynylenedibenzoic acid. Phys. Chem. Chem. Phys. 2001, 3, 4501-4507. [CrossRef]

22. Cyrański, M.; Jezierska, A.; Klimentowska, P.; Panek, J.J.; Sporzyński, A. Impact of intermolecular hydrogen bond on structural properties of phenylboronic acid: Quantum chemical and X-ray study. J. Phys. Org. Chem. 2008, 21, 472-482. [CrossRef]

23. Desiraju, G.R.; Steiner, T. The Weak Hydrogen Bond: In Structural Chemistry and Biology; International Union of Crystal: New York, NY, USA, 2001; Volume 9.

24. Maciejewska, D.; Rasztawicka, M.; Wolska, I.; Anuszewska, E.; Gruber, B. Novel 3,3'-diindolylmethane derivatives: Synthesis and cytotoxicity, structural characterization in solid state. Eur. J. Med. Chem. 2009, 44, 4136-4147. [CrossRef] [PubMed]

25. Vallejos, M.; Peruchena, N.M. Analisis aim y nbo del enlace de hidrogeno aromatico C-H... $\pi$ en el complejo $\mathrm{C}_{2} \mathrm{H}_{2} / \mathrm{C}_{6} \mathrm{H}_{6}$. FACENA 2006, 22, 43-63.

26. Oliveira, B.G.; Pereira, F.S.; de Araújo, R.; Ramos, M.N. The hydrogen bond strength: New proposals to evaluate the intermolecular interaction using DFT calculations and the AIM theory. Chem. Phys. Lett. 2006, 427, 181-184. [CrossRef]

27. Tian, S.X.; Xu, K.Z.; Huang, M.-B.; Chen, X.J.; Yang, J.L.; Jia, C.C. Theoretical study on infrared vibrational spectra of boric-acid in gas-phase using density functional methods. J. Mol. Struct. THEOCHEM 1999, 469, 223-227. [CrossRef]

28. Zarandi, M.; Salimi Beni, A. Synthesis and DFT calculation on novel derivatives of Bis (indolyl) methanes. J. Mol. Struct. 2016, 1119, 404-412. [CrossRef]

29. Karabacak, M.; Sinha, L.; Prasad, O.; Asiri, A.M.; Cinar, M. An experimental and theoretical investigation of Acenaphthene-5-boronic acid: Conformational study, NBO and NLO analysis, molecular structure and FT-IR, FT-Raman, NMR and UV spectra. Spectrochim. Acta Part. A Mol. Biomol. Spectrosc. 2013, 115, 753-766. [CrossRef] [PubMed]

30. Escobedo-González, R.; Méndez-Albores, A.; Villarreal-Barajas, T.; Aceves-Hernández, J.M.; Miranda-Ruvalcaba, R.; Nicolás-Vázquez, I. A theoretical study of 8-chloro-9-hydroxy-aflatoxin B1, the onversion product of aflatoxin B1 by neutral electrolyzed water. Toxins 2016, 8, 225. [CrossRef] [PubMed]

31. Escobedo-González, R.G.; Pérez Martínez, H.; Nicolás-Vázquez, M.I.; Martínez, J.; Gómez, G.; Serrano, J.N.; Carranza Téllez, V.; Vargas-Requena, C.L.; Miranda Ruvalcaba, R. Green production of indolylquinones, derivatives of perezone, and related molecules, promising antineoplastic compounds. J. Chem. 2016, 2016, 1-10. [CrossRef]

32. Cambre, J.N.; Sumerlin, B.S. Biomedical applications of boronic acid polymers. Polymer (Guildf) 2011, 52, 4631-4643. [CrossRef]

33. Türk, D.; Hall, M.D.; Chu, B.F.; Ludwig, J.A.; Fales, H.M.; Gottesman, M.M.; Szakács, G. Identification of compounds selectively killing multidrug-resistant cancer cells. Cancer Res. 2009, 69, 8293-8301. [CrossRef] [PubMed]

34. Domingo, L.R.; R'ios-Gutiérrez, M.; Pérez, P. Applications of the conceptual density functional theory indices to organic chemistry reactivity. Molecules 2016, 21, 748. [CrossRef] [PubMed]

35. Braga, R.C.; Alves, V.M.; Fraga, C.A.M.; Barreiro, E.J.; de Oliveira, V.; Andrade, C.H. Combination of docking, molecular dynamics and quantum mechanical calculations for metabolism prediction of 3,4-methylenedioxybenzoyl-2-thienylhydrazone. J. Mol. Model. 2012, 18, 2065-2078. [CrossRef] [PubMed]

36. Escobedo-González, R.; Vargas-Requena, C.; Moyers-Montoya, E.; Aceves-Hernández, J.; Nicolás-Vázquez, M.; Miranda-Ruvalcaba, R. In silico study of the pharmacologic properties and cytotoxicity pathways in cancer cells of various indolylquinone analogues of perezone. Molecules 2017, 22, 1060. [CrossRef] [PubMed] 
37. Lahari, B.L.; Rajkumar, T.; Reddy, L.S.S.; Reddy, Y.S.R.; Sivudu, G.; Krishna, P.N. In-silico design, synthesis and biological evaluation of some Michael adducts from chalcones. Inven. Rapid Med. Chem. 2015, 4, 1-14.

38. Domingo, L.R.; Pérez, P.; Sáez, J.A. Understanding the local reactivity in polar organic reactions through electrophilic and nucleophilic Parr functions. RSC Adv. 2013, 3, 1486-1494. [CrossRef]

39. Benabadji, S.H.; Wen, R.; Zheng, J.-B.; Dong, X.-C.; Yuan, S.-G. Anticarcinogenic and antioxidant activity of diindolylmethane derivatives. Acta Pharmacol. Sin. 2004, 25, 666-671. [PubMed]

40. Huang, Z.; Zuo, L.; Zhang, Z.; Liu, J.; Chen, J.; Dong, L.; Zhang, J. 3,3'-Diindolylmethane decreases VCAM-1 expression and alleviates experimental colitis via a BRCA1-dependent antioxidant pathway. Free Radic. Biol. Med. 2011, 50, 228-236. [CrossRef] [PubMed]

41. Peklak-Scott, C.; Smitherman, P.K.; Townsend, A.J.; Morrow, C.S. Role of glutathione S-transferase P1-1 in the cellular detoxification of cisplatin. Mol. Cancer Ther. 2008, 7, 3247-3255. [CrossRef] [PubMed]

42. Deppmeier, B.J.; Driessen, A.J.; Hehre, T.S.; Hehre, W.J.; Johnson, J.A.; Klunzinger, P.E.; Leonard, J.M.; Pham, I.N.; Pietro, W.J.; Jianguo, Y.; et al. Spartan 06, Wavefunction Inc.: Irvine, CA, USA, 2006.

43. Frisch, M.; Trucks, G.W.; Schlegel, H.B.; Scuseria, G.E.; Robb, M.A.; Cheeseman, J.R.; Scalmani, G.; Barone, V.; Mennucci, B.; Petersson, G.A.; et al. Gaussian 09, revision D. 01; Gaussian, Inc.: Wallingford, CT, USA, 2009.

44. Lee, C.; Yang, W.; Parr, R.G. Development of the Colle-Salvetti correlation-energy formula into a functional of the electron density. Phys. Rev. B 1988, 37, 785. [CrossRef]

45. Beke, A.D. Density-functional exchanges-energy approximation with correct asymptotic behavior. Phys. Rev. A 1988, 38, 3098-3100. [CrossRef]

46. Becke, A.D. Density-functional thermochemistry. III. The role of exact exchange. J. Chem. Phys. 1993, 98, 5648-5652. [CrossRef]

47. Krishnan, R.; Binkley, J.S.; Seeger, R.; Pople, J.A. Self-consistent molecular orbital methods. XX. A basis set for correlated wave functions. J. Chem. Phys. 1980, 72, 650-654. [CrossRef]

48. Gill, P.M.W.; Johnson, B.G.; Pople, J.A.; Frisch, M.J. The performance of the Becke-Lee-Yang-Parr (B-LYP) density functional theory with various basis sets. Chem. Phys. Lett. 1992, 197, 499-505. [CrossRef]

49. Hariharan, P.C.; Pople, J.A. The influence of polarization functions on molecular orbital hydrogenation energies. Theor. Chem. Acc. Theory Comput. Model. (Theor. Chim. Acta) 1973, 28, 213-222. [CrossRef]

50. Baker, J. An algorithm for the location of transition states. J. Comput. Chem. 1986, 7, 385-395. [CrossRef]

51. Clark, T.; Chandrasekhar, J.; Spitznagel, G.W.; Schleyer, P.V.R. Efficient diffuse function-augmented basis sets for anion calculations. III. The 3-21+ G basis set for first-row elements, Li-F. J. Comput. Chem. 1983, 4, 294-301. [CrossRef]

52. Schlegel, H.B. An efficient algorithm for calculating abinitio energy gradients using s, p Cartesian Gaussians. J. Chem. Phys. 1982, 77, 3676-3681. [CrossRef]

53. Schlegel, H.B. Optimization of equilibrium geometries and transition structures. J. Comput. Chem. 1982, 3, 214-218. [CrossRef]

54. Wojtulewski, S.; Grabowski, S.J. Different donors and acceptors for intramolecular hydrogen bonds. Chem. Phys. Lett. 2003, 378, 388-394. [CrossRef]

55. Koch, U.; Popelier, P.L.A. Characterization of $\mathrm{CHO}$ hydrogen bonds on the basis of the charge density. J. Phys. Chem. 1995, 99, 9747-9754. [CrossRef]

56. Nicolás-Vázquez, I.; Pérez-Caballero, G.; Jiménez, A.G.; Rangel, G.G.; Ruvalcaba, R.M. A novel azocompound, 2-(4-phenylazoaniline)-4-phenylphenol: Spectroscopic and quantum-chemical approach. Int. J. Quantum Chem. 2013, 113, 1107-1115. [CrossRef]

57. Bader, R.F.W. AIM2000 Program Package; Version 2.0; McMaster University: Hamilton, ON, Canada, 2002.

58. Handy, N.C.; Murray, C.W.; Amos, R.D. Study of methane, acetylene, ethene, and benzene using Kohn-Sham theory. J. Phys. Chem. 1993, 97, 4392-4396. [CrossRef]

59. Stephens, P.J.; Devlin, F.J.; Chabalowski, C.F.; Frisch, M.J. Ab initio calculation of vibrational absorption and circular dichroism spectra using density functional force fields. J. Phys. Chem. 1994, 98, 11623-11627. [CrossRef]

60. Devlin, F.J.; Finley, J.W.; Stephens, P.J.; Frisch, M.J. Ab initio calculation of vibrational absorption and circular dichroism spectra using density functional force fields: A comparison of local, nonlocal, and hybrid density functionals. J. Phys. Chem. 1995, 99, 16883-16902. [CrossRef]

61. Lee, S.Y.; Boo, B.H. Density functional theory study of vibrational spectra of anthracene neutral and radical cation. Bull. Korean Chem. Soc. 1996, 17, 754-759. 
62. Zhang, R.-Z.; Li, X.-H.; Zhang, X.-Z. Molecular structure, vibrational spectra and NBO analysis on $1 N$-acetyl-3-(2,4dichloro-5-fluoro-phenyl)-5-(p-methyl-phenyl)-2-pyrazoline using DFT method. Indian J. Pure Appl. Phys. 2011, 49, 731-739.

63. Kurt, M.; Sertbakan, T.R.; Özduran, M.; Karabacak, M. Infrared and Raman spectrum, molecular structure and theoretical calculation of 3,4-dichlorophenylboronic acid. J. Mol. Struct. 2009, 921, 178-187. [CrossRef]

64. Bühl, M.; Kaupp, M.; Malkina, O.L.; Malkin, V.G. The DFT route to NMR chemical shifts. J. Comput. Chem. 1999, 20, 91-105. [CrossRef]

65. Perera, S.A.; Nooijen, M.; Bartlett, R.J. Electron correlation effects on the theoretical calculation of nuclear magnetic resonance spin-spin coupling constants. J. Chem. Phys. 1996, 104, 3290-3305. [CrossRef]

66. Cossi, M.; Barone, V.; Cammi, R.; Tomasi, J. Ab initio study of solvated molecules: a new implementation of the polarizable continuum model. Chem. Phys. Lett. 1996, 255, 327-335. [CrossRef]

67. Cances, E.; Mennucci, B.; Tomasi, J. A new integral equation formalism for the polarizable continuum model: Theoretical background and applications to isotropic and anisotropic dielectrics. J. Chem. Phys. 1997, 107, 3032-3041. [CrossRef]

68. Kohn, W.; Becke, A.D.; Parr, R.G. Density functional theory of electronic structure. J. Phys. Chem. 1996, 100, 12974-12980. [CrossRef]

69. Chattaraj, P.K.; Sarkar, U.; Elango, M.; Parthasarathi, R.; Subramanian, V. Electrophilicity as a possible descriptor of the kinetic behaviour. arXiv, 2005.

70. Glossman-Mitnik, D. G3-B3 calculation of the molecular structure and descriptors of isomeric thiadiazoles. J. Mol. Struct. THEOCHEM 2005, 725, 27-30. [CrossRef]

71. Walch, S.P. Model calculations of the electron affinities and ionization potentials of DNA. Chem. Phys. Lett. 2003, 374, 496-500. [CrossRef]

72. Parr, R.G.; Szentpaly, L.V.; Liu, S. Electrophilicity index. J. Am. Chem. Soc. 1999, 121, 1922-1924. [CrossRef]

73. Domingo, L.R.; Chamorro, E.; Pérez, P. Understanding the reactivity of captodative ethylenes in polar cycloaddition reactions. A theoretical study. J. Org. Chem. 2008, 73, 4615-4624. [CrossRef] [PubMed]

74. Adams, S. Metaprint2D-React Metabolic Product Predictor. Available online: http:/ /www-metaprint2d.ch. cam.ac.uk/metaprint2d-react (accessed on 25 February 2016).

75. Correa-Basurto, J.; Bello, M.; Rosales-Hernandez, M.C.; Hernández-Rodríguez, M.; Nicolás-Vázquez, I.; Rojo-Domínguez, A.; Flores-Sandoval, C.A. QSAR, docking, simulation and quantum mechanics studies to explore the recognition properties of cholinesterase binding sites. Chem. Biol. Interact. 2014, 209, 1-13. [CrossRef] [PubMed]

76. Boyer, S.; Arnby, C.H.; Carlsson, L.; Smith, J.; Stein, V.; Glen, R.C. Reaction Site Mapping of Xenobiotic Biotransformations. J. Chem. Inf. Model. 2007, 47, 583-590. [CrossRef] [PubMed]

77. Boyer, S.; Zamora, I. New methods in predictive metabolism. J. Comput. Aided Mol. Des. 2002, 16, 403-413. [CrossRef] [PubMed]

78. Piechota, P.; Cronin, M.T.; Hewitt, M.; Madden, J.C. Pragmatic approaches to using computacional methods to predict xenobiotic metabolism. J. Chem. Inf. Model. 2013, 53, 1282-1293. [CrossRef] [PubMed]

Sample Availability: Not Available.

(C) 2017 by the authors. Licensee MDPI, Basel, Switzerland. This article is an open access article distributed under the terms and conditions of the Creative Commons Attribution (CC BY) license (http:/ / creativecommons.org/licenses/by/4.0/). 